\title{
Experimental investigation of subsurface defect detection in concretes by infrared thermography and convection heat exchange
}

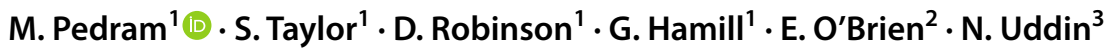

Received: 30 September 2021 / Revised: 6 January 2022 / Accepted: 7 January 2022 / Published online: 28 January 2022

(c) The Author(s) 2022

\begin{abstract}
Infrared thermography (IRT) is a non-destructive technique capable of detection and localisation of hidden subsurface defects in components of transportation infrastructure, such as concrete bridges, thereby contributing to structural health monitoring (SHM). Addressing the lack of research on subsurface defect detection in concretes by convection heat exchange, and regarding the importance of laboratory studies for proper implementation of IRT, this paper presents results from recent laboratory investigations of IRT on concrete slabs with simulated hidden defects using a convective thermal excitation mechanism. The concrete slabs in this study had simulated defects ranging $5-25 \mathrm{~mm}$ in depth from the surface. These studies show the effect of initial temperature, heating/cooling process, temperature range and defect depth on thermal contrast in the concrete slabs. Furthermore, this paper compares the performance of the IRT as a non-contact sensor and thermocouples attached to the surface, in the evaluation of the thermal contrast on slabs with various defect depth. The dependence of maximum thermal contrast on the initial temperature and defect depth is explored using multivariate linear regression.
\end{abstract}

Keywords Infrared thermography $\cdot$ Concrete $\cdot$ Subsurface defect detection · Thermal contrast $\cdot$ Convection heat exchange . Thermocouples $\cdot$ Structural health monitoring

\section{Introduction}

The need for optimal operation of bridges as critical elements of the transportation infrastructure, requires research and development into structural health monitor-

M. Pedram

mpedram01@qub.ac.uk

S. Taylor

s.e.taylor@qub.ac.uk

D. Robinson

des.robinson@qub.ac.uk

G. Hamill

g.a.hamill@qub.ac.uk

E. O'Brien

eugene.obrien@ucd.ie

N. Uddin

nuddin@uab.edu

1 Department of Civil Engineering, Queen's University Belfast, Belfast BT7 1NN, Northern Ireland, UK

2 School of Civil Engineering, University College Dublin, Dublin D04V1W8, Ireland

3 Department of Civil, Construction, and Environmental Engineering, School of Engineering, University of Alabama at Birmingham, Birmingham, AL 35294, USA ing (SHM) techniques for early-stage diagnosis of defects to prevent disruptive or catastrophic outcomes and ensure their safe future performance. This involves scheduled or periodic data collection of the responses of structural components to different excitation mechanisms (preferably in a non-destructive manner with minimum disturbance to the operation of the structure) and objective interpretation of data [1]. Many components of bridges, such as deck, girders, soffit, abutment, pier, and foundations are often made from concrete. In many of these concrete components, the damage remains concealed well after the initiation of corrosion in steel reinforcement. Concrete degradation and corrosion of steel reinforcement are the major reasons for the deterioration of concrete infrastructure due to the accumulation of iron oxides at the bond interface, which weakens their adhesion and forms voids between the concrete and the rebar [2]. Generation of calcium carbonate in the cover region, cracking in the concrete adjacent to the 
steel and the presence of aggressive substances, such as chlorides, result in more rapid erosion of the passive layer around the steel and the formation of corrosion pits and initiation of corrosion. Subsequently, the accumulation of iron oxide in the interface between steel and concrete (that occupy much more volume), leads to formation and expansion of cracks in the concrete, detachment of material and the formation of subsurface air-filled voids and cracks [3-5].

Infrared thermography (IRT) as a non-destructive and commercially available remote sensing method [6] has been the subject of state-of-the-art researches for condition monitoring $[7,8]$ and quantification of hidden subsurface anomalies such as delamination and voids in concrete bridges [3, 9-13]. The mechanism of subsurface damage detection and characterisation by active thermography is outlined in the literature $[7,11,14-17]$ in adequate technical detail. When slabs with subsurface defects are subject to thermal excitation (heating or cooling), the sound and defective materials will change the temperature at different rates due to the difference in heat diffusion rates. In a heating-up process, the concrete with the subsurface defect will be warmer than the undamaged concrete and, in a cooling-down process the defective concrete will be colder than the undamaged concrete.

IRT has the advantage of being non-contact as the thermal sensor is not in contact with the target object and nonintrusive as it causes minimal disruption to the bridge performance. Besides, the infrared radiation is not dangerous for the operators, and usually it requires less training hours compared to other non-destructive techniques. Two-dimensional measurements in form of images, ease of portability of equipment, fast response rate and a variety of post-processing techniques are among the other merits of IRT [6, $7,9,18]$. On the other hand, challenges and uncertainties regarding the favourable data collection environment [3, 12] and favourable data collection time window, variations of surface emissivity, reflected or background temperature and atmospheric attenuation [9], the data collection mode (whether terrestrial or aerial) [19], the IR camera specification and calibration [14], the geometry, the depth of the subsurface defect (or concrete cover) [11] and low thermal conductivity of concrete that needs loads of energy for thermal stimulation [20] affects the practical implementation of IRT for subsurface damage detection in concrete bridges. Hiasa et al. [10, 11] have mentioned and addressed some inconsistencies and challenges of detecting defects of different size and depth in concrete by IRT during heating or cooling cycles encountered by other researchers [16, 21, 22]. In addition, Watase et al. proposed a methodology to predict the favourable time windows for thermography of bridge deck and soffit based on ambient air temperature measurements, and weather data from a website [23].
The reports from the studies performed in cooperation with the department of transportation (DOT) in several states in the United States (US) [24, 25], have highlighted the importance of laboratory evaluations for proper implementation of condition assessment of concrete bridge components and for training of the potential users of IRT [26]. These studies along with numerical modelling can illuminate uncertainties related to defect geometry, reinforcement density, concrete material properties, anomalies at locations like tendon ducts and various excitation heat source [27, 28]. Furthermore, they can provide a basis to understand the heat flow mechanism in the defected concrete, and to develop practical objective data interpretation schemes. To mention such efforts, reference could be made to rigorous active thermography laboratory investigations of Cotic et al. [29] on four specimens with 50 different defects of a range of sizes and depths to propose a detectability scheme based on size and depth of defects. Based on the significance of the time of maximum thermal contrast $\left(t_{\max }\right)$ as a criterion, they defined a defect to be detectable up to a depth of $90 \%$ of its characteristic length. Although such detactibility schemes might be valid for the adopted heat source and setup in a specific study [20], they are valuable because they provide a basis for decision-making for the practical implementation of IRT.

Therefore, the importance of laboratory studies for correct implementation of IRT and the challenges mentioned in the literature of IRT damage detection, give rise to the necessity for more fundamental research and benchmark study into the effect of variables of subsurface defect detection such as the geometry of defects and the thermal excitation mechanism on concrete surface thermal contrast. This paper presents the results from recent experimental investigations of subsurface void detection on six concrete slabs cast from a normal strength concrete mix, which is typical of that used in bridge construction in the United Kingdom (UK). The subsurface defect was simulated using embedded voids at depths ranging from 5 to $25 \mathrm{~mm}$ from the surface. Regarding a lack of research on convective heating and cooling heat exchange [7] it is adopted as an excitation mechanism in this study and the effect of initial temperature, heating or cooling processes at various temperature ranges and defect depth on the temporal variation of thermal contrast and maximum thermal contrast were investigated. These observations reveal the relationship between the maximum thermal contrast and initial temperature (temperature range), as well as the relationship between thermal contrast and defect depth based on Infrared tests. Moreover, a general relationship between initial temperature (temperature range) and defect depth (D) as predictors of the maximum thermal contrast, is developed and discussed. The thermal contrast achieved using IRT is compared with the contrast achieved using thermocouples attached to the surface (contact-based measurement). This comparison shows the performance of 
both methods in the evaluation of surface thermal contrast against variation of subsurface defect depth.

\section{Material and method}

\subsection{Concrete models}

The specimens of the tests were prepared using a mix proportion adopted in previous studies by Grattan [30] that is typical of UK bridge construction. The mix is composed of $375 \mathrm{~kg} / \mathrm{m}^{3}$ Portland cement, $612 \mathrm{~kg} / \mathrm{m}^{3}$ medium graded natural sand, $1137 \mathrm{~kg} / \mathrm{m}^{3}$ coarse aggregate of maximum $10 \mathrm{~mm}$ diameter and $225 \mathrm{~kg} / \mathrm{m}^{3}$ water. The concrete was mixed in accordance with BS EN 1881: Part 125 (1986) and BS 812: Part 2 (1995) to cast six slabs (one slab without voids as a control sample and five voided slabs) plus control cubes for thermal property measurements. The thermal conductivity, thermal diffusivity, and volumetric specific heat of the cubes, in accordance with the BS EN ISO 22007-2 transient plane heat source (hot disc) method, were 1.504 $\mathrm{Wm}^{-1} \mathrm{~K}^{-1}, 0.6501 \mathrm{~mm}^{2} \mathrm{~s}^{-1}$ and $2.313 \mathrm{MJm}^{-3} \mathrm{~K}^{-1}$, respectively. Figure 1(a) shows the front view of these models and the embedded void is shown with a dashed line. Figure 1(b), provides the top view of the models with dimensions of the voids underneath the top surface.

Table 1 shows the thicknesses and depths of the $100 \times 100 \mathrm{~mm}$ voids in the $250 \times 250 \times 100 \mathrm{~mm}$ test slabs and the test slab code. The samples are coded as SQ100D5 to D25, in which the SQ100 refers to surface shape and size of defects, and D5 to D25 refer to the thickness of concrete cover. The thickness of concrete cover or the depth of void underneath the surface was 5, 10, 15, 20 and $25 \mathrm{~mm}$ for models SQ100-D5 to SQ100-D25, respectively. In the experimental studies $[3,11,29,31,32]$ on the effect of geometry and depth of subsurface defects using IRT, void-like and delamination-like defects are simulated by casting pieces of polystyrene and timber of different sizes and at various depths in the concrete. Polystyrene-made
Table 1 Test slabs and the thickness of concrete cover

\begin{tabular}{lll}
\hline Slab code & $\begin{array}{l}\text { Dimensions of embed- } \\
\text { ded polystyrene }(\mathrm{mm})\end{array}$ & $\begin{array}{l}\text { Layer thickness of } \\
\text { the concrete cover } \\
(\mathrm{mm})\end{array}$ \\
\hline $\begin{array}{l}\text { Control specimen } \\
\text { (no void) }\end{array}$ & - & - \\
SQ100-D5 & $100 \times 100 \times 95$ & 5 \\
SQ100-D10 & $100 \times 100 \times 90$ & 10 \\
SQ100-D15 & $100 \times 100 \times 85$ & 15 \\
SQ100-D20 & $100 \times 100 \times 80$ & 20 \\
SQ100-D25 & $100 \times 100 \times 75$ & 25 \\
\hline
\end{tabular}

inclusions are widely used in the simulation of artificial delamination and voids because the concrete over them has shown similar temperature contrast patterns to actual defects [29, 33]. To simulate the defect (void) in the slabs, polystyrene foams of $95,90,85,80$ and $75 \mathrm{~mm}$ thickness were glued to the bottom face of the plywood formwork (shuttering) and after removing the formwork, the foams were left embedded in the slabs. This way, 5, 10, 15, 20 and $25 \mathrm{~mm}$ concrete covers were created above the voids in the slabs. All tests were referenced to a control model, of the same mix design, that did not have a void/defect within it. In this study, all the slabs were prepared and cast with the same mix proportions and casting procedure, and they were kept in similar curing conditions for 28 days. Therefore, it can be assumed that the thermal properties of the concrete are similar throughout the experiment programme. Besides, the plywood formworks and polystyrene foams used for casting the slabs were prepared by a skilled technician after precise measurements using calibrated equipment (e.g., vernier calliper of $0.01 \mathrm{~mm}$ precision). Any change to the assumed thickness of cover during casting and curing of the slabs caused by shrinkage of the mix are assumed to have negligible effect on the reported results as all the slabs have undergone a similar production process.
Fig. 1 Dimensions of the concrete slabs and the simulated defects (colour figure online)

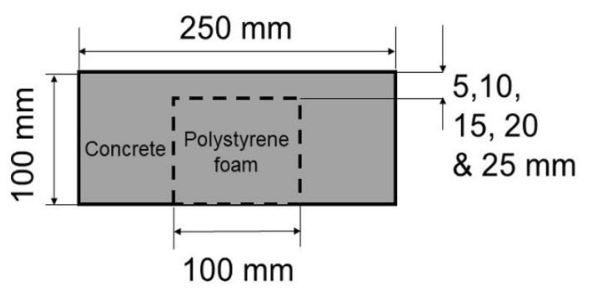

(a) Side view

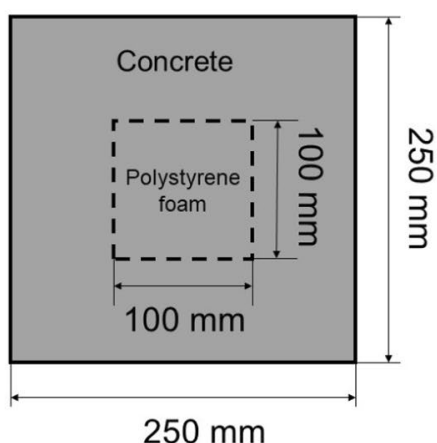

(b) Top view 


\subsection{Test apparatus}

The specifications and details of the apparatus used for the testing are given in Table 2. In these experiments, a thermal camera, a data acquisition module, environmental chamber, hand-held thermo-hygrometer, insulation box, tripod and thermocouples were used.

\subsection{Experimental procedure}

The main goal of the experimental programme was to discover the trend in the variation of thermal contrast with the depth of void cover in heating and cooling temperature ranges and initial temperatures (abbreviated as IT hereafter). A controlled laboratory environment, without any major source of thermal emissions was selected as the thermography room to ensure consistency in the IR experiments. This is a windowless room located in the basement of the civil engineering department with the walls made of bricks and has doors made of wood. Prior to the experiments, the ambient temperature and relative humidity of air in the room were measured as they affect the atmospheric transmission and attenuation of radiated heat from the slabs. The variation of room temperature during each test was within the range of $\pm 1{ }^{\circ} \mathrm{C}$. This was monitored by the thermo-hygrometer and a thermocouple during thermocouple measurements to ensure that the temperature remained in the range. Furthermore, the background temperature (that is reflected from the target surface during thermography), as the significant factor influencing the thermography, was measured following the standard procedure specified in ASTM E 1862-97. The measured reflected temperature, ambient temperature, and humidity, as well as the camera vision to target distance, were necessary inputs to the camera's software to measure the target temperature. The details and equations of temperature and atmospheric attenuation calculation by FLIR cameras are included in the literature $[34,35]$ and the cameras' manual [36]. In this study, the tests were performed using an uncooled long-wave IR (LWIR) thermal imager with thermal sensitivity of less than $0.05^{\circ} \mathrm{C}$ and the performance of other detector types or technologies e.g., a cooled short-wave IR (SWIR) is not explored. To ensure the consistency of the testing environment, several angles, and distances of the camera to the target, were investigated. Using a standard ASTM E 1862-97 test, with a diffuse reflector of negligible emissivity $(\leq 0.05)$, distances of 500,1000 and $1500 \mathrm{~mm}$ and angles of camera to the target of $0,15,30,45$ and $60^{\circ}$ were examined. Table 3 presents the coefficient of variation $(\mathrm{COV})$ of the temperature measured on the diffuse reflector board in this testing environment. The smaller COV value (closer to zero), indicates less variation and dispersion of the reflected temperature from other objects or heat sources on the diffuse reflector board. The COV values are extremely low, which indicates negligible reflection in the selected test environment. Zero degree or the straight-on position, however, leads to the highest reflection from the operator and camera; hence it is not adopted in these studies. In Table 3, four distance and angle pairs of $\left(500 \mathrm{~mm}, 45^{\circ}\right)$, $\left(1000 \mathrm{~mm}, 45^{\circ}\right),\left(500 \mathrm{~mm}, 60^{\circ}\right)$ and $\left(1000 \mathrm{~mm}, 60^{\circ}\right)$ have the least $\mathrm{COV}$ of reflected temperatures. Among these four

Table $3 \mathrm{COV}$ of measurements during reflection tests using the IR camera

\begin{tabular}{llllll}
\hline \multirow{5}{*}{ Distance $(\mathrm{mm})$} & 0 & 15 & 30 & 45 & 60 \\
\cline { 2 - 6 } & 0.0192 & 0.0117 & 0.0071 & 0.0055 & 0.0050 \\
1000 & 0.0117 & 0.0071 & 0.0064 & 0.0059 & 0.0054 \\
1500 & 0.0089 & 0.0094 & 0.0087 & 0.0084 & 0.0068 \\
\hline
\end{tabular}

Table 2 Test apparatus

\begin{tabular}{|c|c|c|}
\hline Number & Equipment & Specification \\
\hline 1 & Thermocouple & $\begin{array}{l}\text { Fast response, } 0.25 \mathrm{~mm} \text { diameter beaded wire type } \mathrm{K} \text { thermocouple, with miniature plug and maxi- } \\
\text { mum service temperature of } 260^{\circ} \mathrm{C}\end{array}$ \\
\hline 2 & Data acquisition module & $\begin{array}{l}\text { Eight-channel module with cold junction compensation (CJC), resolution of } 0.1 \text { degrees, conversion } \\
\text { time } 100 \mathrm{~ms} \text {, and resolution of 20-bits }\end{array}$ \\
\hline 3 & Thermal camera & $\begin{array}{l}\text { FLIR B335 thermal camera with an uncooled Microbolometer, Long wave IR (LWIR) thermal imager } \\
\text { resolution of } 320 \times 240 \text { pixels, and spectral range of } 7.5-13 \mu \mathrm{m} \text {. Thermal sensitivity of this IR } \\
\text { camera is less than } 0.05^{\circ} \mathrm{C} \text { at } 30^{\circ} \mathrm{C} \text { with } 50 \mathrm{mK} \text { NETD, } 1.36 \mathrm{mrad} \text { spatial resolution (Instantaneous } \\
\text { field of view (IFOV)) and } 25^{\circ} \times 19^{\circ} \text { field of view. The } 3.1 \text { Mega pixel visual imager of this camera } \\
\text { has a } 2048 \times 1536 \text { pixels array with the FOV of } 53^{\circ} \times 41^{\circ}\end{array}$ \\
\hline 4 & Environmental chamber & $\begin{array}{l}\text { Astell Scientific Environmental chamber type } \mathrm{HD} 1000 \mathrm{EBC} 276 \text {, control type Eurotherm 821, temper- } \\
\text { ature range of }-40 \text { to } 100{ }^{\circ} \mathrm{C} \text { with twin condenser fans and R502 refrigerant for heating and cooling }\end{array}$ \\
\hline 5 & Hand-held thermo-hygrometer & Simultaneous measurement of temperature and humidity of the ambient environment \\
\hline 6 & Insulation Box & $\begin{array}{l}\text { Timber insulated frame to match dimensions of the slabs and cover all faces except the top surface } \\
\text { (which is exposed to convection heating and cooling excitations) and to represent continuity in a real } \\
\text { bridge structure }\end{array}$ \\
\hline
\end{tabular}


options of camera to target distance and angle, all tests were performed with $1000 \mathrm{~mm}$ distance and $45^{\circ}$ angle. The $60^{\circ}$ angle was not adopted, because it was exceedingly oblique for the dimensions of the slabs while the effect of reflection was like $45^{\circ}$. In addition, $1000 \mathrm{~mm}$ was selected as the distance for full coverage of the slab in camera's field of view. In general, the variation in reflected temperature was negligible in this environment and it was considered close to the ambient temperature as an average.

The emissivity of dry concrete is in the range of 0.92 to 0.98 depending on the surface condition and roughness. In these studies, the emissivity of concrete was adjusted to 0.95 as commonly reported in the research literature [19, $31,37]$ and emissivity tables in technical reports and sensor users' manual [36]. In general, the emissivity measurement based on the standard procedures is challenging and not reliable due to the variations in the surrounding and detector temperature as discussed in detail by Chen and Chen [38]. Therefore, the value from the emissivity tables was adopted in this study.

Figure 2 presents a schematic of the apparatus and the procedures of the tests. For initial temperature adjustments and thermography testing, the slabs were placed in the insulation boxes. In the insulation box, the surface over top of the void was exposed to convection heat exchange with air in chamber or ambient air in the thermography room and the other surfaces were insulated; thereby the heating or cooling of the samples was unidirectional. In addition, the box prevented the edge effect and facilitated the temperature uniformity of the samples while transferring and handling them from the chamber to the testing environment. An accurately calibrated Astell environmental chamber was used to bring the samples to the planned initial temperature (Fig. 3a). To ensure the uniformity of the slabs' initial temperature prior to the tests, the samples were kept in the chamber overnight (at least $14 \mathrm{~h}$ ) before the day of the experiment. This was concluded based on the insights from prior temperature measurements using thermocouples attached to the bottom faces of slabs. After the slab reached the planned initial temperature for an experiment, it was enclosed in the box (Fig. 3b) to preserve the initial temperature during transfer to the thermography room. The temperature of the chamber was set to two degrees Centigrade more than the planned initial temperature for the cooling-down thermography experiments and cooled to two degrees less than the planned initial temperature for the heating-up thermography experiments. This was to compensate for possible initial heat exchange during transfer of the slabs from the environmental chamber to the thermography room. Starting arrangements for each test were in the range of five to ten minutes. As mentioned earlier, prior to the initiation of the IRT measurements, the room temperature and relative humidity $(\mathrm{RH})$ were measured and used as an input to the camera's software as parameters of the test. After the initial arrangements, the lid of the insulation box was removed from the front and kept behind the sample to further limit heat exchange from back of the slabs. Removing the lid was considered as the effective start of test, and the operator captured IR images from the sample surface as the sample cooled-down/heated-up. Figure 3(c) shows a typical slab during test without thermocouples and Fig. 3(d) shows a slab during test with thermocouples. The IRT measurements of the slabs with thermocouples are not reported in this paper.

The insulation box mitigated the disrupting effect of edge heating or cooling in the thermal contrast image, which is a challenge in thermography studies [8], especially for the case of higher concrete cover to the void. Figure 4 shows the temperature distribution on the slabs with and without
Fig. 2 Schematic overview of the testing arrangement and apparatus (colour figure online)

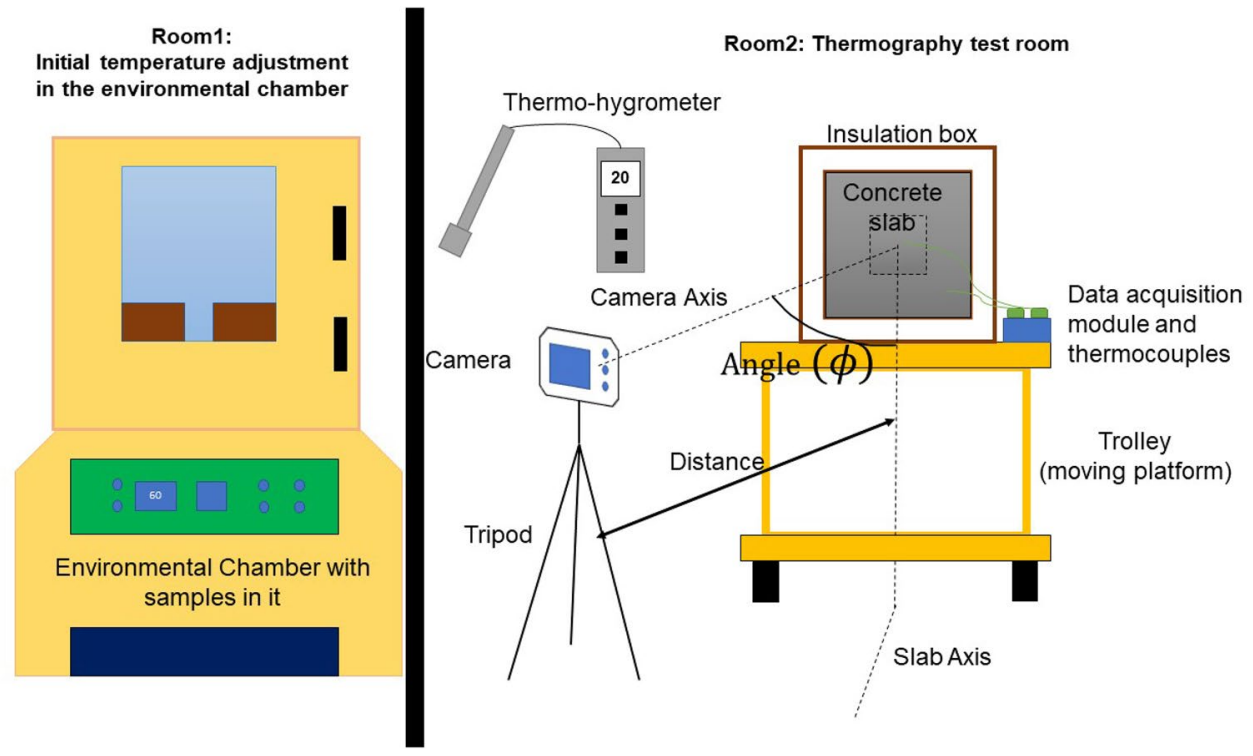




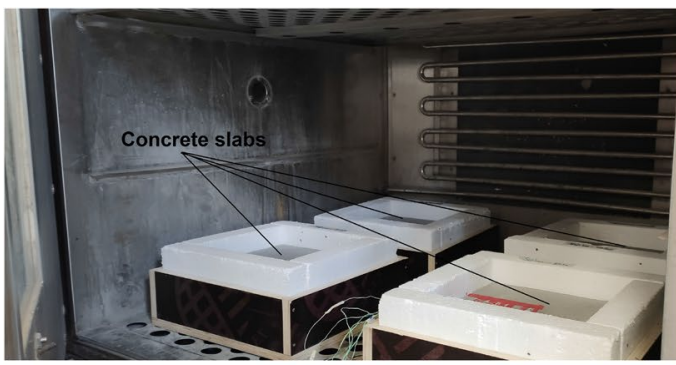

(a) Convection stimulation of slabs from top

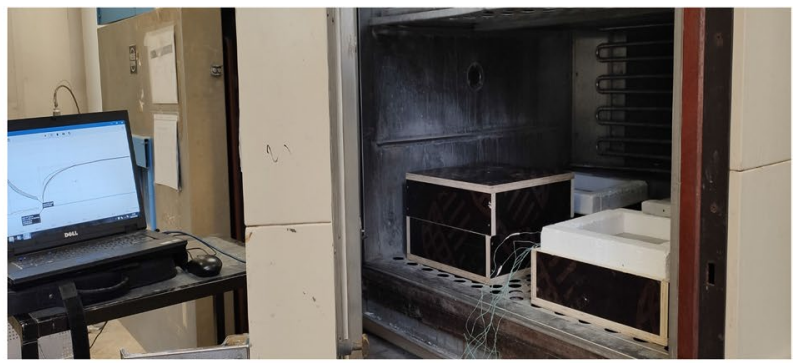

(b) A sample enclosed in the box before test surface

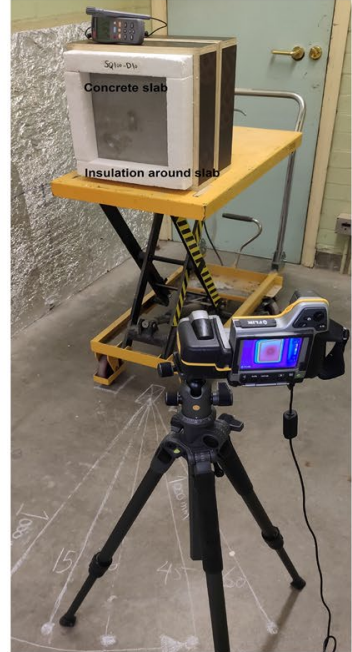

(c) A typical sample during thermography measurement without thermocouples

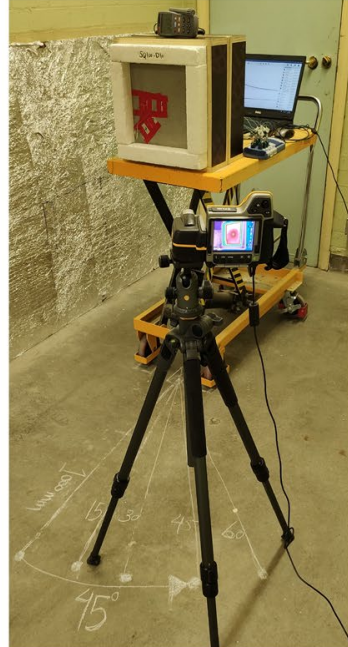

(d) A typical sample during thermography measurement with thermocouples

Fig. 3 Thermal excitation of the slabs and test setup (colour figure online)

box at a certain point in time (40 min in Fig. 4) after the start of a typical cool down test from $45^{\circ} \mathrm{C}$. According to Fig. 4(a), by using the box, a subsurface void of $25 \mathrm{~mm}$ depth shows a thermal contrast distinguished by the isotherm adjustments. However, without using the box around the slab, this void does not show an observable sign of damage even with isotherm adjustment, Fig. 4(b). Without using the box, the contrast from the void did not show up prior to or after the time shown in this figure. The edge cooling effect was greater than the thermal contrast from the void on the surface for the cases of the slabs with the deepest void (e.g., $25 \mathrm{~mm}$ ) without the insulation box around the slab. A comparison of the SQ100-D5 model with box (Fig. 4c) and without box (Fig. 4d) shows that without using the box, the edge cooling effect due to three-dimensional heat dissipation obscures the observability of the void's thermal contrast. However, the thermal contrast from the void is clearly observed without the disruption from edge cooling effect. The insulation on the edges affects the surface temperature and thermal contrast quantitively as it is a change in the boundary condition.

\section{Results}

\subsection{Studied test cases}

In this section, the studied test cases (selected from the full set of observations) are outlined in Table 4. In this table, the tests are classified into six sets based on the initial temperature of the slabs at the start of the test. Furthermore, each test indicator introduces the sample, initial and final temperature, as well as the temperature transition process. For instance, D10_-20H19.8 shows slab SQ100-D10 in a heat-up test starting from $-20{ }^{\circ} \mathrm{C}$ to the ambient (room) temperature of $19.8{ }^{\circ} \mathrm{C}$. As the tests were conducted on different dates and times, the ambient temperature and humidity of tests did vary slightly. The first and second set of experiments 
Fig. 4 The effect of insulation box on IRT observations at a certain point in time ( $40 \mathrm{~min}$ in this case) after the start of a typical cool-down test from $45^{\circ} \mathrm{C}$ (colour figure online)

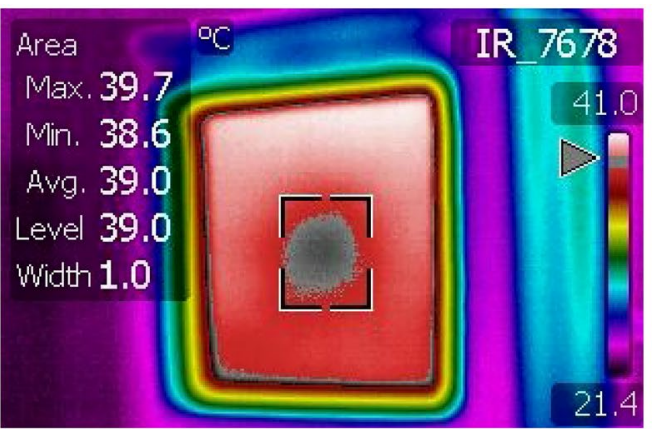

(a) SQ100-D25 with box

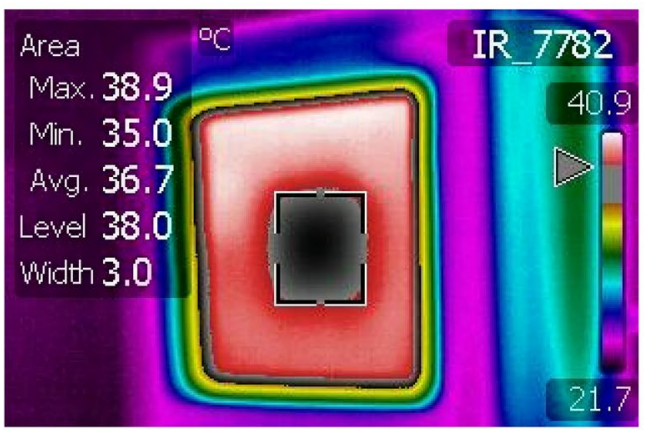

(c) SQ100-D5 with box

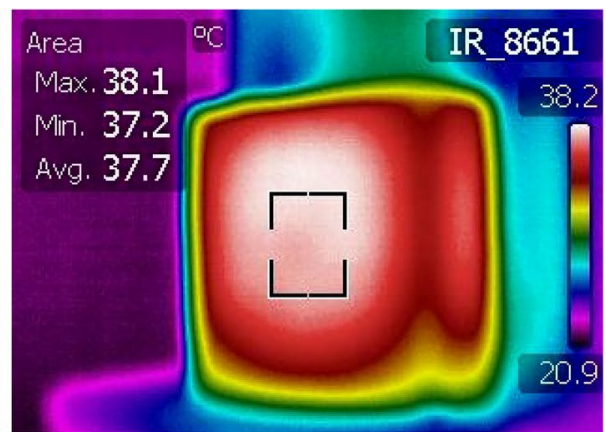

(b) SQ100-D25 without box

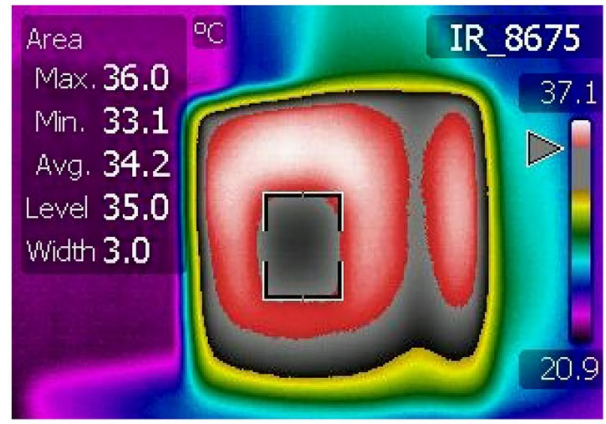

(d) SQ100-D5 without box were performed using both infrared camera (IR) and thermocouples (TC).

\subsection{Temporal evolution of the thermal contrast on the surface}

After a slab was removed from the environmental chamber it was kept in the designated location (the thermography room), and the Joint Photographic Experts Group (JPEG) format IR images of the target surface were captured at irregular intervals in a sufficient timespan that the temperature difference on the surface reaches and passes the maximum thermal contrast. The images were then post-processed to achieve the temperature equivalence of each pixel using a routine developed based on the features and capabilities of FLIR for MATLAB. The routine performed the temperature extraction on several points on the surface using their corresponding pixels (average of $4 \times 4$ pixels in the vicinity of the point) to calculate the difference of temperature at points $\mathrm{i}\left(T_{i}\right)$ and $\mathrm{j}\left(T_{j}\right)$ on the surface $\left(\Delta T_{i j}\right)$. This difference defined in Eq. 1, is generally known and referred to as thermal contrast or temperature contrast $[7,17,39]$.

$\Delta T_{i j}(t)=T_{i}(t)-T_{j}(t)$

Figure 5 shows the points considered on the target surface to calculate the thermal contrast. Point \#5 is the marked location at the centre of the void cover (on the surface of the defective concrete) and the other points are considered on the surface of the sound (intact) concrete $50 \mathrm{~mm}$ away from the slab's edge and $25 \mathrm{~mm}$ away from the edge of the subsurface defect. In calculation of surface thermal contrast, the point at the centre of the void cover is selected for the temperature record on the defective concrete and points at least $10 \mathrm{~mm}$ away from the edge of the subsurface defect are considered as the points on the sound (intact) concrete [10, 11]. This section presents the temporal evolution of the thermal contrast on the surface of the slabs for set \#1 (heating-up process) and set \#2 (cooling-down process).

Figure 6 presents the temporal evolution of the thermal contrast of IR measurements of point \#5 and \#7 (IR 5-IR 7) and IR measurements of point \#5 and \#4 (IR 5-IR 4), in the set \#1 tests with initial temperature of $0{ }^{\circ} \mathrm{C}$ and heating-up to ambient temperature. According to this figure, models D5 and D25 exhibit the highest and lowest temperature difference among the voided models, respectively. According to Fig. 6(a), the temperature at the centre of the control sample (point \#5) is slightly higher than the temperature of point \#7. This is because the slabs were placed vertically in front of the camera during the test and at this positioning, point \#7 is at a lower position compared to point \#5.

For further illustration, the temperature contour of the control specimen is presented in Fig. 7. This figure shows the temperature contours for the control specimen at the start of the test and sixty minutes after the start. Figure 7(a) shows the contour plots at the initial stage of the test. At this stage, the sample is at a homogenous and uniform temperature distribution at about $-1.0{ }^{\circ} \mathrm{C}$ and there is no significant 
Table 4 Summary of studied test cases

\begin{tabular}{|c|c|c|c|c|c|c|c|c|}
\hline Set No. & & Sample & SQ100-D5 & SQ100-D10 & SQ100-D15 & SQ100-D20 & SQ100-D25 & Control Specimen \\
\hline \multirow[t]{5}{*}{$\begin{array}{l}\text { Set \#1 } \\
\mathrm{IT}=0{ }^{\circ} \mathrm{C}\end{array}$} & \multirow[t]{3}{*}{ IR } & $\begin{array}{l}\text { Room temperature } \\
\left({ }^{\circ} \mathrm{C}\right)\end{array}$ & 20.2 & 20.2 & 20.2 & 20.2 & 20.2 & 20.2 \\
\hline & & Room RH (\%) & 62 & 62 & 62 & 65.4 & 65.4 & 62 \\
\hline & & Test Indicator & $\begin{array}{l}\text { D5 } \\
0 \mathrm{H} 20.2\end{array}$ & $\begin{array}{l}\text { D10_ } \\
0 \mathrm{H} 20.2\end{array}$ & $\begin{array}{l}\text { D15_ } \\
0 \mathrm{H} 20.2\end{array}$ & $\begin{array}{l}\mathrm{D} 20 \ldots \\
0 \mathrm{H} 20.2\end{array}$ & $\begin{array}{l}\mathrm{D} 25 \\
0 \mathrm{H} 20.2\end{array}$ & $\begin{array}{l}\mathrm{CS}_{-} \\
0 \mathrm{H} 20.2\end{array}$ \\
\hline & \multirow[t]{2}{*}{$\mathrm{TC}$} & $\begin{array}{l}\text { Room temperature } \\
\left({ }^{\circ} \mathrm{C}\right)\end{array}$ & 22 & 22 & 21.5 & 21 & 21 & - \\
\hline & & Test Indicator & $\begin{array}{l}\mathrm{D} 5 \\
0 \mathrm{H} 22\end{array}$ & $\begin{array}{l}\mathrm{D} 10_{-} \\
\mathrm{OH} 22\end{array}$ & $\begin{array}{l}\text { D15_ } \\
0 \mathrm{H} 21.5\end{array}$ & $\begin{array}{l}\mathrm{D} 20 \ldots \\
\mathrm{OH} 21\end{array}$ & $\begin{array}{l}\mathrm{D} 25 \\
\mathrm{OH} 21\end{array}$ & - \\
\hline \multirow[t]{5}{*}{$\begin{array}{l}\text { Set \#2 } \\
\mathrm{IT}=45^{\circ} \mathrm{C}\end{array}$} & \multirow[t]{3}{*}{ IR } & $\begin{array}{l}\text { Room temperature } \\
\left({ }^{\circ} \mathrm{C}\right)\end{array}$ & 19 & 20 & 19 & 20 & 20 & 20 \\
\hline & & Room RH (\%) & 63.2 & 61 & 63.2 & 61 & 61 & 61 \\
\hline & & Test Indicator & $\begin{array}{l}\mathrm{D} 5 \\
45 \mathrm{C} 19\end{array}$ & $\begin{array}{l}\mathrm{D} 10 \\
45 \mathrm{C} 20\end{array}$ & $\begin{array}{l}\text { D15 } \\
45 \mathrm{C} 19\end{array}$ & $\begin{array}{l}\text { D20_ } \\
45 \mathrm{C} 20\end{array}$ & $\begin{array}{l}\mathrm{D} 25_{-} \\
45 \mathrm{C} 20\end{array}$ & $\begin{array}{l}\mathrm{CS}_{-} \\
45 \mathrm{C} 20\end{array}$ \\
\hline & \multirow[t]{2}{*}{$\mathrm{TC}$} & $\begin{array}{l}\text { Room temperature } \\
\left({ }^{\circ} \mathrm{C}\right)\end{array}$ & 21.5 & 21.3 & 21.3 & 20.7 & 21.7 & - \\
\hline & & Test Indicator & $\begin{array}{l}\text { D5 } \\
45 \mathrm{C} 21.5\end{array}$ & $\begin{array}{l}\mathrm{D} 10_{-} \\
45 \mathrm{C} 21.3\end{array}$ & $\begin{array}{l}\mathrm{D} 15 \\
45 \mathrm{C} 21.3\end{array}$ & $\begin{array}{l}\mathrm{D} 20_{-} \\
45 \mathrm{C} 20.7\end{array}$ & $\begin{array}{l}\text { D25_- } \\
45 \mathrm{C} 21.7\end{array}$ & - \\
\hline \multirow[t]{3}{*}{$\begin{array}{l}\text { Set } \# 3 \\
\text { IT }=-20{ }^{\circ} \mathrm{C}\end{array}$} & \multirow[t]{3}{*}{ IR } & $\begin{array}{l}\text { Room temperature } \\
\left({ }^{\circ} \mathrm{C}\right)\end{array}$ & 19.7 & 19.8 & 20.4 & 20.8 & 20.8 & 20.4 \\
\hline & & Room RH (\%) & 68 & 67 & 66 & 60 & 60 & 66 \\
\hline & & Test Indicator & D5_-20H19.7 & D10_-20H19.8 & D15_-20H20.4 & D20_-20H20.8 & D25_-20H20.8 & CS_-20H 20.4 \\
\hline \multirow[t]{3}{*}{$\begin{array}{l}\text { Set \#4 } \\
\mathrm{IT}=60^{\circ} \mathrm{C}\end{array}$} & \multirow[t]{3}{*}{ IR } & $\begin{array}{l}\text { Room temperature } \\
\left({ }^{\circ} \mathrm{C}\right)\end{array}$ & 20 & 19.3 & 20 & 20 & 19.3 & 20 \\
\hline & & Room RH (\%) & 68.5 & 63.5 & 68.5 & 68.5 & 63.5 & 68.5 \\
\hline & & Test Indicator & $\begin{array}{l}\text { D5 } \\
60 \mathrm{C} 20\end{array}$ & $\begin{array}{l}\text { D10 } \\
60 \mathrm{C} 19.3\end{array}$ & $\begin{array}{l}\text { D15 } \\
60 C 20\end{array}$ & $\begin{array}{l}\mathrm{D} 20 \\
60 \mathrm{C} 20\end{array}$ & $\begin{array}{l}\text { D25 } \\
60 C 19.3\end{array}$ & $\begin{array}{l}\mathrm{CS}_{-} \\
60 \mathrm{C} 20\end{array}$ \\
\hline \multirow[t]{3}{*}{$\begin{array}{l}\text { Set } \# 5 \\
\mathrm{IT}=-15^{\circ} \mathrm{C}\end{array}$} & \multirow[t]{3}{*}{ IR } & $\begin{array}{l}\text { Room temperature } \\
\left({ }^{\circ} \mathrm{C}\right)\end{array}$ & 20.2 & 20.8 & 21.7 & 20.9 & 20.2 & - \\
\hline & & Room RH (\%) & 70.9 & 70.3 & 68.6 & 68.4 & 70.9 & \\
\hline & & Test Indicator & $\begin{array}{l}\text { D5 } \\
-15 \mathrm{H} 20.2\end{array}$ & $\begin{array}{l}\mathrm{D} 10- \\
-15 \mathrm{H} 20.8\end{array}$ & $\begin{array}{l}\text { D15_ } \\
-15 \mathrm{H} 21.7\end{array}$ & $\begin{array}{l}\mathrm{D} 20- \\
-15 \mathrm{H} 20.9\end{array}$ & $\begin{array}{l}\mathrm{D} 25 \\
-15 \mathrm{H} 20.2\end{array}$ & - \\
\hline \multirow[t]{3}{*}{$\begin{array}{l}\text { Set } \# 6 \\
\text { IT }=55^{\circ} \mathrm{C}\end{array}$} & \multirow[t]{3}{*}{ IR } & $\begin{array}{l}\text { Room temperature } \\
\left({ }^{\circ} \mathrm{C}\right)\end{array}$ & 21.3 & 22 & 22 & 21.4 & 21.4 & - \\
\hline & & Room RH (\%) & 71 & 68.5 & 68.5 & 71 & 72 & - \\
\hline & & Test Indicator & $\begin{array}{l}\text { D5_- } \\
55 \mathrm{C} 21.3\end{array}$ & $\begin{array}{l}\mathrm{D} 10 \\
55 \mathrm{C} 22\end{array}$ & $\begin{array}{l}\mathrm{D} 15_{-} \\
55 \mathrm{C} 22\end{array}$ & $\begin{array}{l}\mathrm{D} 20- \\
55 \mathrm{C} 21.4\end{array}$ & $\begin{array}{l}\mathrm{D} 25_{-} \\
55 \mathrm{C} 21.4\end{array}$ & - \\
\hline
\end{tabular}

temperature contrast from bottom to the top of this slab. Sixty minutes after the start, due to the vertical position of the sample, there was about $1.5^{\circ} \mathrm{C}$ temperature gradient from bottom to top and about 0.6 from bottom to the centre of the slab (Fig. 7b). Owing to the vertical positioning of the specimen during thermography, the sample's surface temperature increases from bottom to top, which is possibly the result of the local variation in the convection coefficient of the air cooled in contact with the cold specimen from bottom to top of the sample as it gets colder in contact to the sample [40]. Further experiments with slabs positioned horizontally will be performed to explore this thermal gradient on the surface of slabs. The range of temperature of these contours varied as they were taken at the start and $60 \mathrm{~min}$ after the start of a transient heat-up process. So, they are shown with different colormaps with labels added to them for convenience of comparison.

In a similar set of tests, the temporal evolution of the thermal contrast on the surface using the thermocouples (TC) attached to the surface at points \#4, \#5 and \#7 (shown in Fig. 5) was also assessed. In these tests, a highly conductive silicone paste and tapes were used to attach the thermocouples on the surface. Figure 8 shows the change in the contrast values through time for the thermocouple measurements for points \#5 and \#7 (TC 5-TC 7) and the thermocouple measurements for points \#5 and \#4 (TC 5-TC 4). Using thermocouples, model D5 and D10 exhibit almost the same thermal contrast at locations \#5 and \#7. Besides, the contrast 


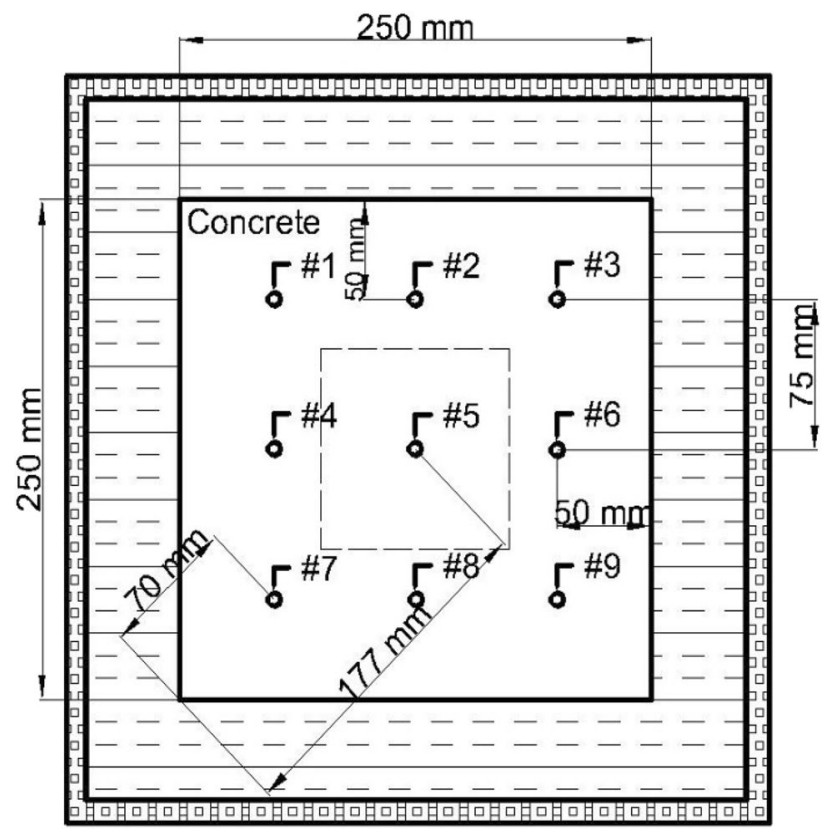

Fig. 5 Points for thermal contrast calculation (colour figure online)

of model D10 and D15 is almost similar at sensor locations \#5 and \#4, and model D25 does not represent a significant difference at this location. It is observed that the trend of the contrast variation is not consistent in two cases when using the thermocouple measurements.

Figure 9 shows the temporal evolution of the temperature difference at the designated locations during IR thermography in set \#2 tests with the samples initially at $45^{\circ} \mathrm{C}$, cooling down to the ambient temperature. In these experiments, the defective concrete (points \#5) cools down faster than the intact concrete (points \#4, and \#7). As a result, the temperature differences appear as negative values.

Figure 10 shows the thermal contrast calculated based on the thermocouple measurement. In this case, Fig. 10(a) shows that the contrasts at sensor locations \#5 and \#7 do not adequately distinguish the contrast of D10, D15 and D20 models. Figure 10(b) shows that the difference of temperature measurements at locations \#5 and \#4 for models D10 and D15 are quite similar. Furthermore, unlike the IR measurements in which the trend of the thermal contrast variation is consistent at the measurement locations, the thermocouple measurements do not exhibit a certain trend at different measurement locations. This is understood by comparing Fig. 10 with Fig. 8.

\subsection{Maximum thermal contrast of the measurements}

To understand the trend of thermal contrast variation with the depth of a defect and the initial temperature (temperature range), the maximum contrast of test cases was adopted. In this study, the maximum contrast of an IR experiment is defined as the maximum value for the difference between temperature of point \#5 that is on top of void cover and the other points that are on the intact concrete surface. This definition of maximum contrast is given in the Eq. 2.

$\Delta T_{\text {max }}=\max \left(T_{\# 5}-T_{i}\right) i=1,2, \ldots, 9$ and $i \neq 5$,

Table 5 compares the maximum thermal contrast of the first and second set of IR experiments and thermocouple (TC) measurements. In addition, this table presents the maximum temperature difference of the third to sixth cases of IR experiments.

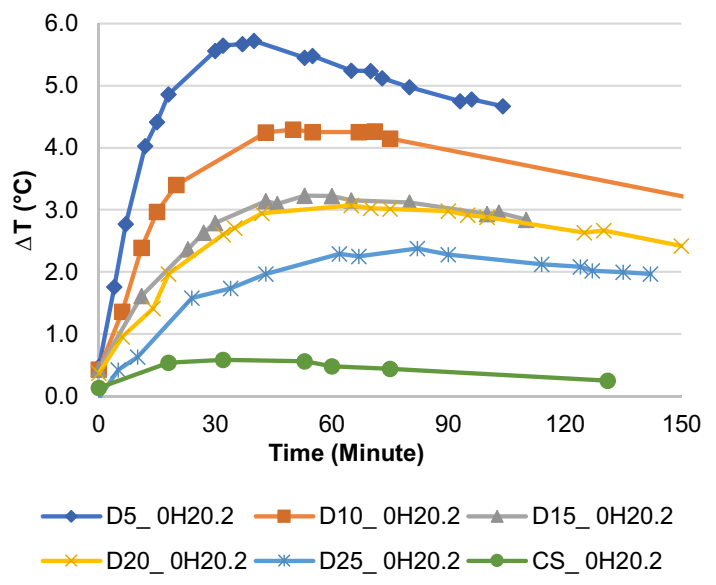

(a) Temperature difference of point \#5 and \#7

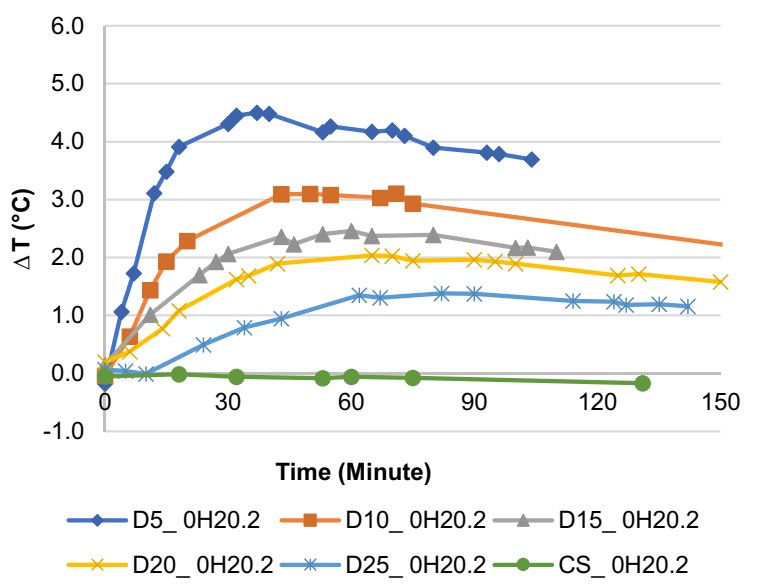

(b) Temperature difference of point \#5 and \#4

Fig. 6 Thermal contrast for set \#1 IR tests from $0{ }^{\circ} \mathrm{C}$ to ambient temperature (colour figure online) 
Fig. 7 Temperature contours of CS_0H20.2 test (colour figure online)

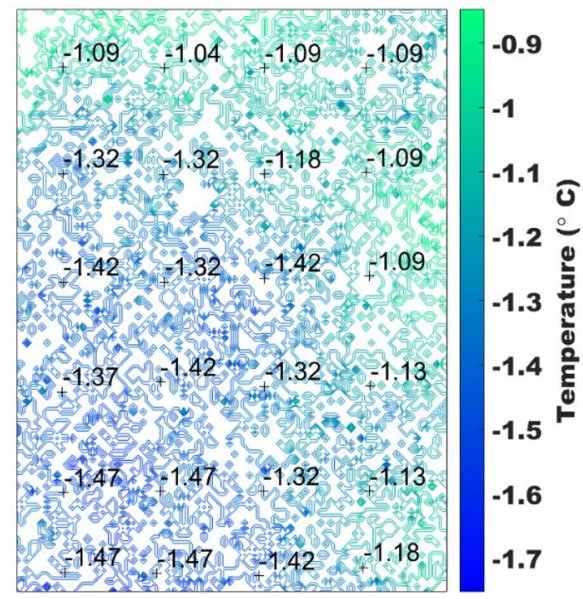

(a) Temperature contours of first image

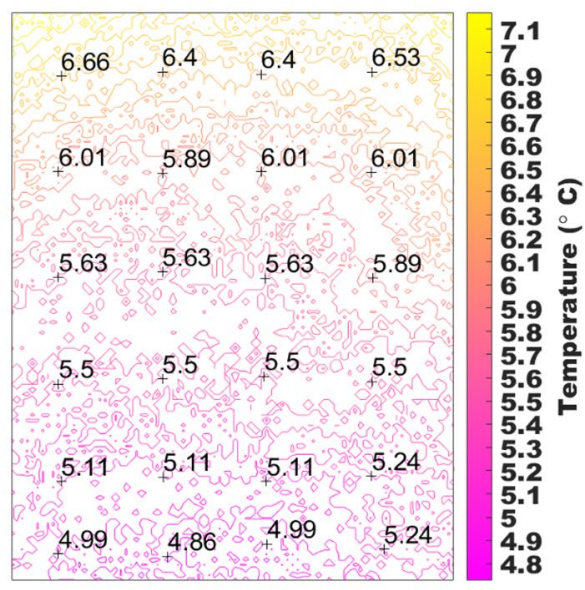

(b) Temperature contours 60 minutes after start

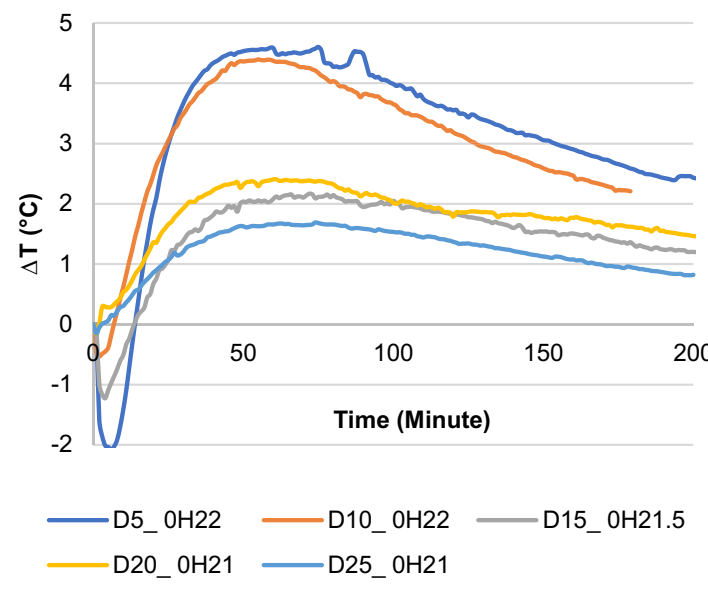

(a) Temperature difference at point \#5 and \#7

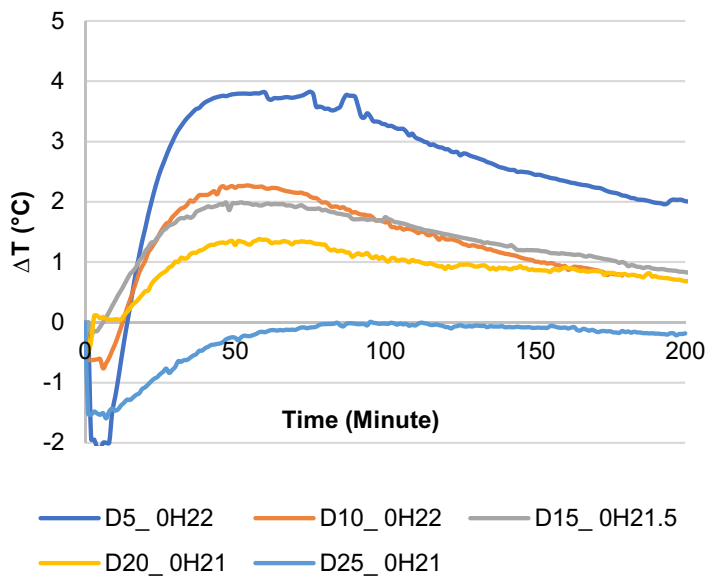

(b) Temperature difference at point \#5 and \#4

Fig. 8 Thermal contrast of set \#1 thermocouple tests from $0{ }^{\circ} \mathrm{C}$ to ambient temperature (colour figure online)

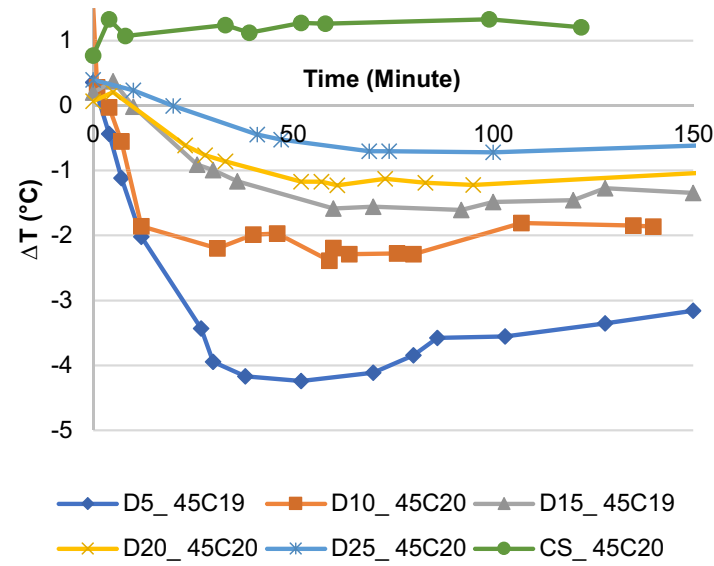

(a) Temperature difference of point \#5 and \#7

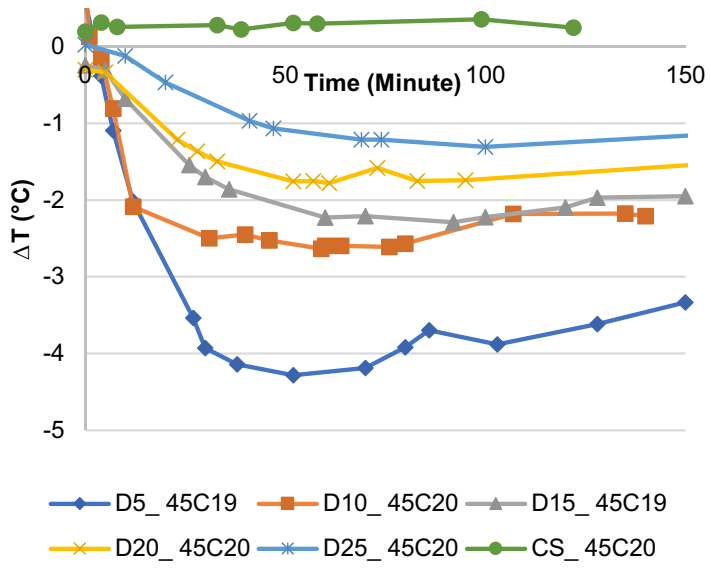

(b) Temperature difference of point \#5 and \#4

Fig. 9 Thermal contrast for set \#2 IR tests from IRT images for $45^{\circ} \mathrm{C}$ to ambient (colour figure online) 


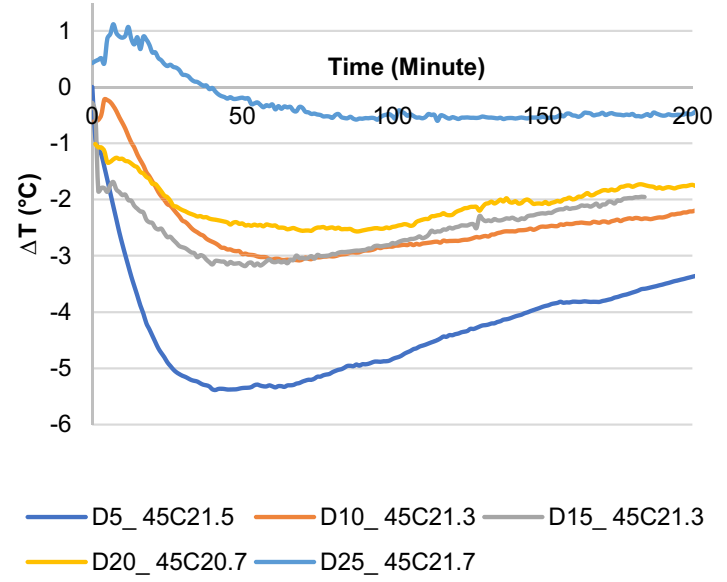

(a) Temperature difference of point \#5 and \#7

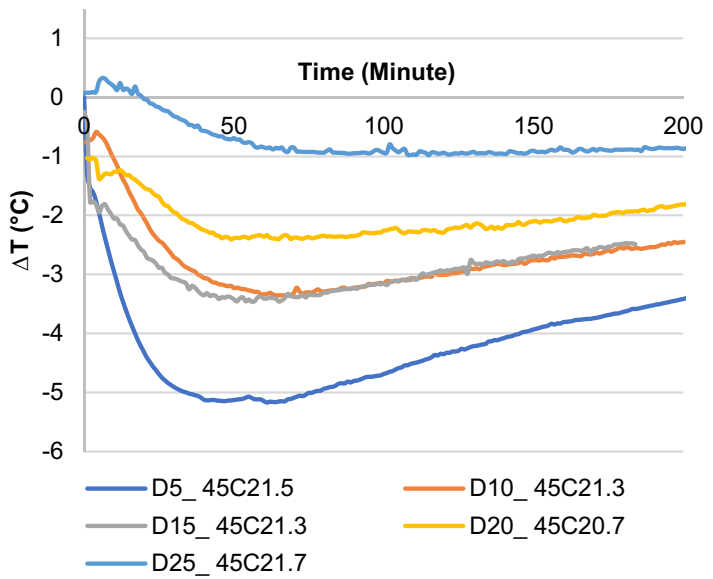

(b) Temperature difference of point \#5 and \#4

Fig. 10 Thermal contrast of set \#2 tests with thermocouples on surface (colour figure online)

Figure 11 plots the absolute values of maximum temperature differences against the defect depth. In this figure, linear, and power function as the non-linear alternative represent the trend of the variations. Power function was selected after the trial of exponential, logarithmic, power, and polynomial functions. Figure 11(a) and (b) compare the maximum contrast achieved in the first set of experiments by IR and TC tests, and Fig. 11(c) and (d) compare the variation of maximum contrast achieved in the second set of experiments by IR and TC, respectively. The functions and corresponding coefficients of determination are included in the legend of the figures.

Further to Fig. 11, Table 6 summaries the trendlines and coefficients of determination (R-squared) for the functions fitted to the absolute maximum thermal contrasts of the other experiment sets (set \#3 to set \#6). For the case of the thermal contrast by IRT in each test set, the power function (non-linear alternative) predicts the observations with slightly higher accuracy than the linear function. For the case of first and second test sets with TC measurements, the linear trendline predicts the data with slightly higher accuracy.

Several initial temperatures of the slabs were examined in these experiments, and the analysis of the data has given a relationship between the variables. Figure 12 shows that initial temperature (and temperature range as a result) has a linear relationship with the variation of maximum thermal contrast of each model. The linear variation of maximum thermal contrast with the initial temperature means that these variables are proportional for each slab. This follows the proportionality of the convection to the heating/cooling temperature range. In the creation of this chart, the real values of the maximum thermal contrasts are adopted. Therefore, the tests with an initial temperature higher than room temperature, have negative $\Delta T_{\max }$ values and the tests with an initial temperature lower than room temperature have positive $\Delta T_{\max }$ values. Graphs of all models intersect with the abscissa at a temperature around the room temperature, indicating that when the temperature range is zero, there will be no thermal contrast. The equations of fitted linear trendlines are included in the legend of this figure. The absolute value of slope (proportionality constant) of these linear trendlines against the defect depth are shown in Fig. 13.

In Fig. 13, linear, and power functions are fitted to the data. The fitted trendlines show that variation of the slope of data lines with the depth of void is better represented by a nonlinear pattern. This is understood by the comparison of the $R$-squared value of the fitted curves. This graph can be considered as the summary of equations for variation of maximum thermal contrast against the depth of void (or thickness of void cover).

The multivariate linear regression of full second-order polynomial function was adopted for further investigation into the relationship of $\Delta T_{\max }$ as the dependent variable, and the initial temperature (IT) and the defect depth $(D)$ as the independent variables. The equation of the fitted surface using a second order function of full terms, is presented in Table 7 and the accuracy of the fit indicator ( $R$-squared), is equal to 0.997 (very close to 1). The Root Mean Squared Error (RMSE) is equal to 0.369 (close to 0 ) and the $p$ value is equal to $1.86 \times 10^{-24}$. This p-value means that at $5 \%$ significance level, all the independent variables contribute to the response variable (the null hypothesis that all parameters do not contribute is rejected) [32] and this model aligns to the data significantly better than a degenerate model of a constant term [41]. This preliminary analysis includes the data from all the experiment sets to distinguish the effective terms in the regression model. Table 7 includes the estimated coefficient, standard error, $t$ statistics, and $p$ value 


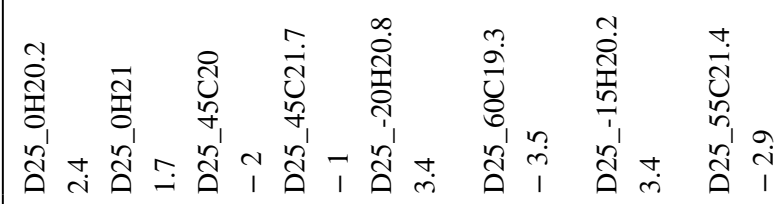

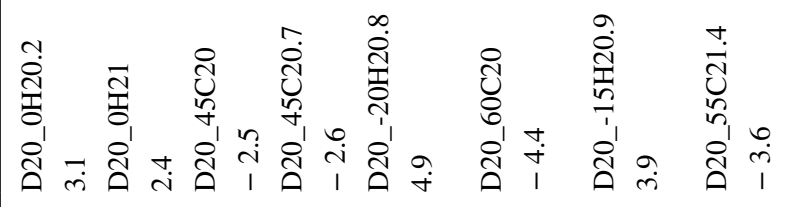

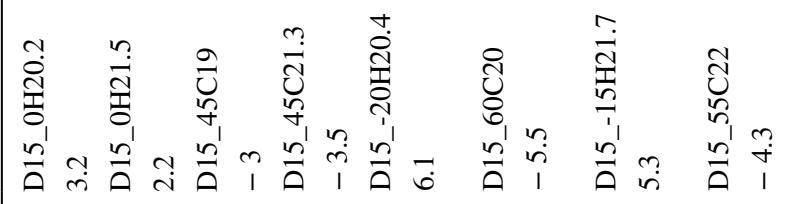

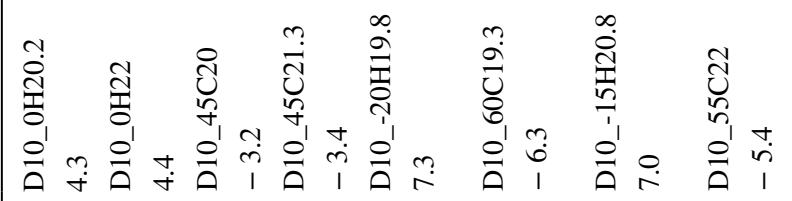

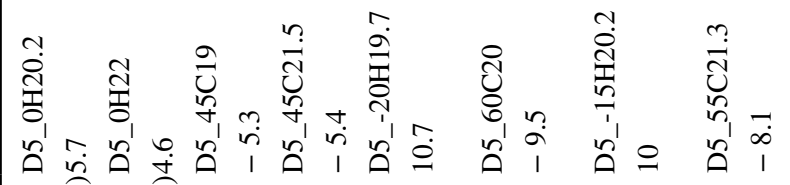

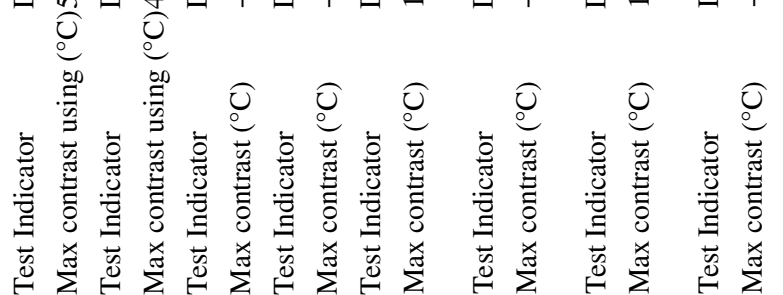

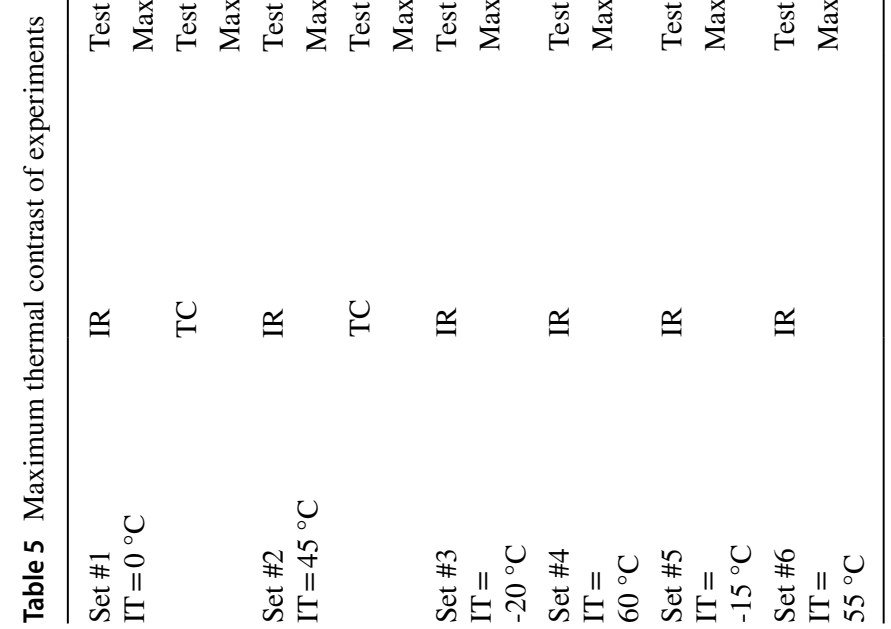




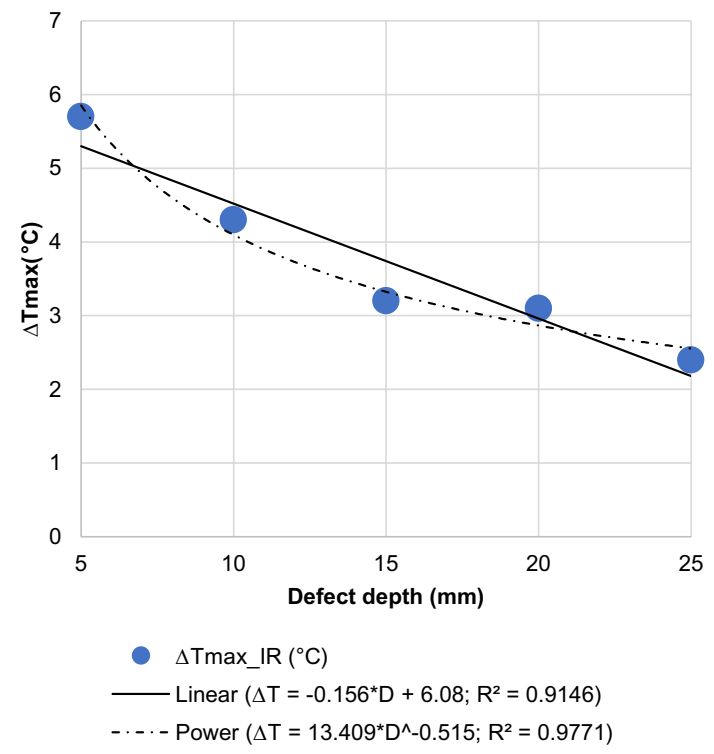

(a) Set 1-IRT experiments $\left(\mathrm{IT}=0^{\circ} \mathrm{C}\right)$

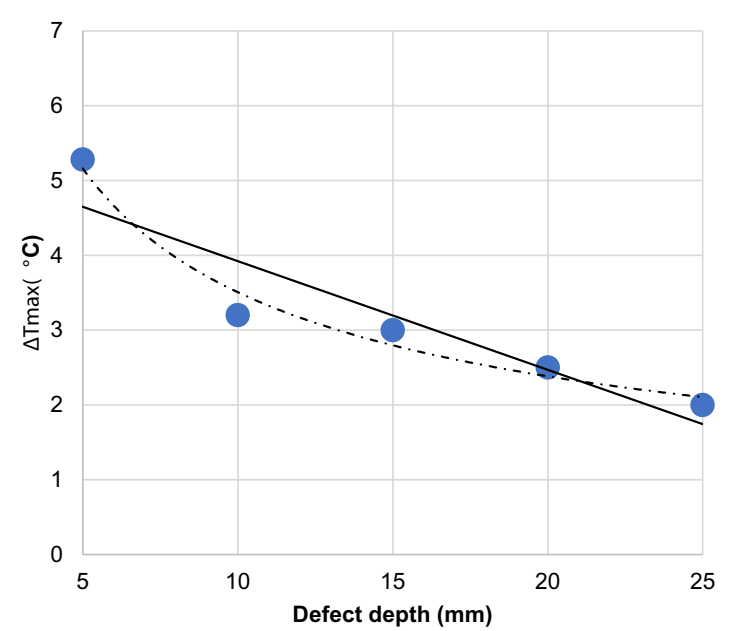

- $\Delta$ Tmax_IR $\left({ }^{\circ} \mathrm{C}\right)$

- Linear $\left(\Delta T=-0.1452 \mathrm{D}+5.3749 ; \mathrm{R}^{2}=0.837\right)$

- . - - Power $\left(\Delta T=12.665 D^{\wedge}-0.558 ; R^{2}=0.9725\right)$

(c) Set 2-IRT experiments $\left(\mathrm{IT}=45^{\circ} \mathrm{C}\right)$

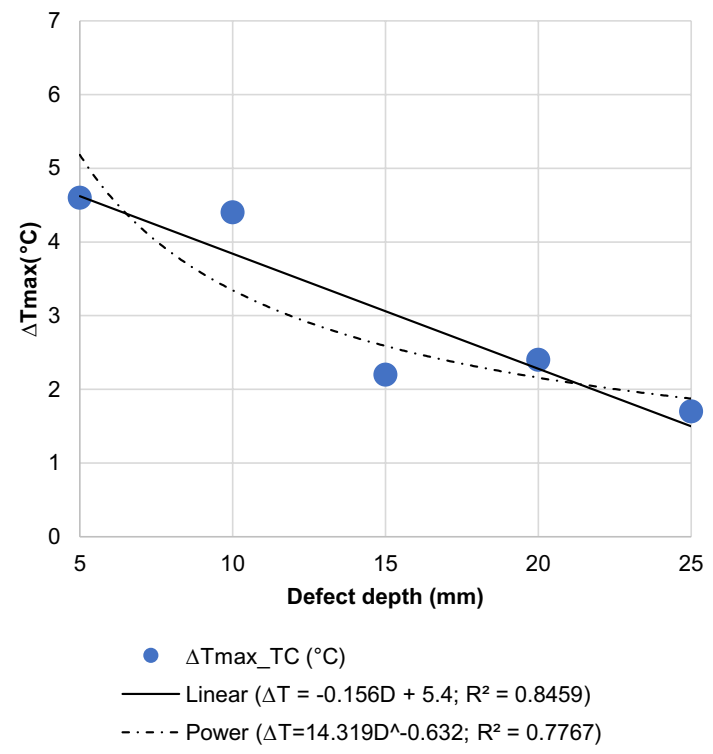

(b) Set 1-Thermocouple experiments $\left(\mathrm{IT}=0^{\circ} \mathrm{C}\right)$

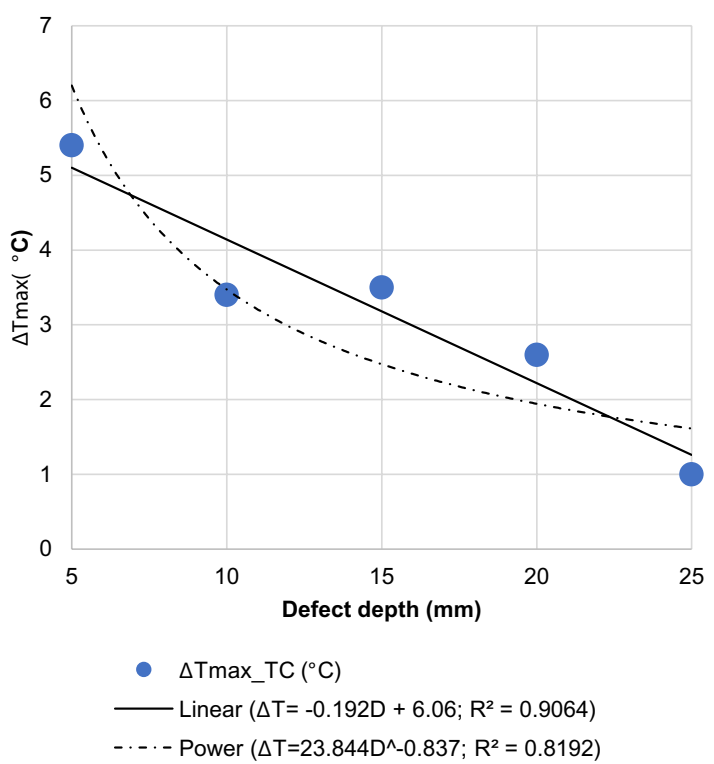

(d) Set 2-Thermocouple experiments $\left(\mathrm{IT}=45^{\circ} \mathrm{C}\right)$

Fig. 11 Variation of the absolute maximum contrast with void depth for the first and second set of IRT and TC tests (colour figure online)

Table 6 Summary of fitted curves to the $\Delta T_{\max }$ against the depth of defect

\begin{tabular}{|c|c|c|c|c|c|}
\hline Function & & $\begin{array}{l}\text { Set \#3 } \\
\text { IT }=-20^{\circ} \mathrm{C}\end{array}$ & $\begin{array}{l}\text { Set \#4 } \\
\text { IT }=60{ }^{\circ} \mathrm{C}\end{array}$ & $\begin{array}{l}\text { Set \#5 } \\
\text { IT }=-15^{\circ} \mathrm{C}\end{array}$ & $\begin{array}{l}\text { Set \#6 } \\
\mathrm{IT}=55^{\circ} \mathrm{C}\end{array}$ \\
\hline Linear & IR & $\begin{array}{l}-0.34 D+11.58 \\
\left(R^{2}=0.9442\right)\end{array}$ & $\begin{array}{l}-0.278 D+10.01 \\
\left(R^{2}=0.9083\right)\end{array}$ & $\begin{array}{l}-0.326 D+10.81 \\
\left(R^{2}=0.9281\right)\end{array}$ & $\begin{array}{l}-0.244 D+8.52 \\
\left(R^{2}=0.9003\right)\end{array}$ \\
\hline Power & IR & $\begin{array}{l}32.493 D^{-0.656} \\
\left(R^{2}=0.9695\right)\end{array}$ & $\begin{array}{l}24.903 D^{-0.588} \\
\left(R^{2}=0.9865\right)\end{array}$ & $\begin{array}{l}31.558 D^{-0.682} \\
\left(R^{2}=0.9819\right)\end{array}$ & $\begin{array}{l}22.303 D^{-0.619} \\
\left(R^{2}=0.9965\right)\end{array}$ \\
\hline
\end{tabular}


Fig. 12 Variation of $\Delta T \max$ $\left({ }^{\circ} \mathrm{C}\right)$ with initial temperature (colour figure online)

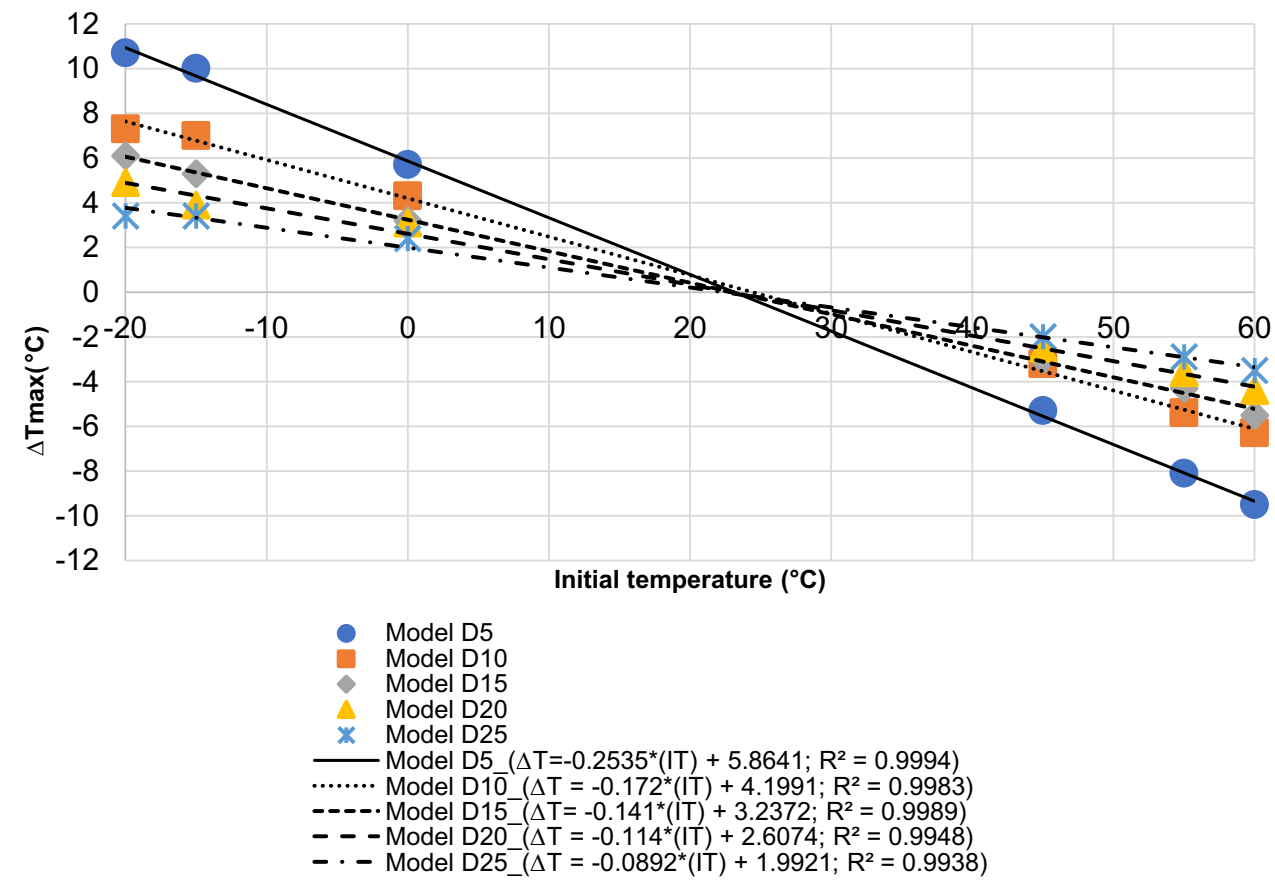

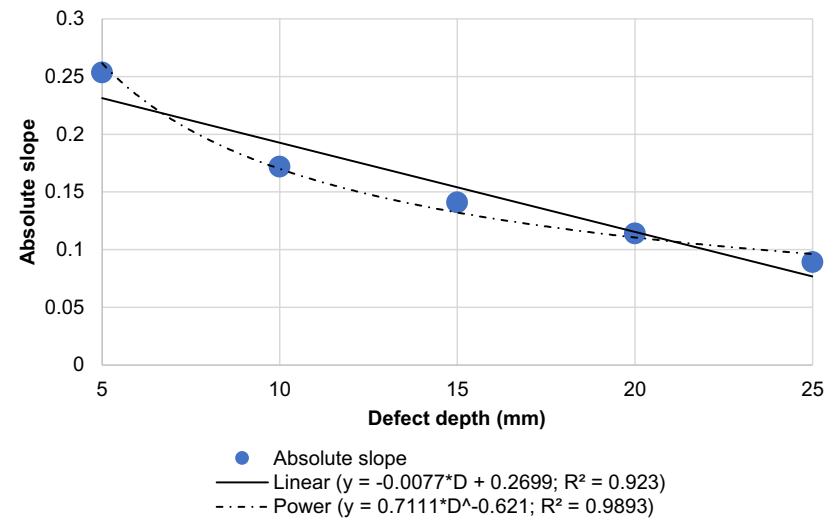

Fig. 13 Variation of absolute slope with void cover (colour figure online)

of the linear multivariate regression procedure. The $t$ statistic evaluates the null hypothesis that the corresponding coefficient is zero against the non-zero alternatives, given the other terms in the model. It is defined as the ratio of estimated coefficient and standard error. The $p$ value for the $t$ statistic, shows the significance of a coefficient (zero or non-zero), given the other predictors in the model. Therefore, this table shows that the terms with initial temperature (IT) raised to the power of two, i.e., $I T^{2}, I T^{2} \times D$, and $I T^{2} \times D^{2}$ that have $p$ values higher than 0.05 , are inadmissible at $5 \%$ significance level given the other terms in the model (the zero value null hypothesis for these coefficients is not rejected) [41]. This further justifies the linear dependence of thermal contrast on the initial temperature and nonlinear dependence of thermal contrast on the defect depth. Moreover, the $t$ statistics of these terms show that their coefficient is less than the standard error, which clarifies their inadmissibility in the model. The final equation achieved based on all measured data sets is presented in Eq. 3 after linear regression with $R$-squared value of 0.996, RMSE of 0.377 and $p$ value of $3.18 \mathrm{e}-28$.

$$
\begin{aligned}
\Delta T_{\max }= & 7.5965-0.3286(I T)-0.3951(D) \\
& +0.0178(I T \times D)+0.00695\left(D^{2}\right) \\
& -3.3575 e-4\left(I T \times D^{2}\right)
\end{aligned}
$$

To complement and validate the regression model, 20 observations in experiment sets \#1 to \#4 were considered in the multivariate analysis of the data without considering the second-order terms of IT that lead to Eq. 4 with R-squared equal to 0.995 , RMSE equal to 0.44 and p-value equal to 1.02e-15. The data in set \#5 and \#6 were kept reserved for validation of this model.

$$
\begin{aligned}
\Delta T_{\max }= & 7.2118-0.3187(I T)-0.3470(D)+0.0165(I T \times D) \\
& +0.0057\left(D^{2}\right)-3.0019 e-4\left(I T \times D^{2}\right)
\end{aligned}
$$

Figure 14 presents the three-dimensional sketch of Eq. 4 and measured data. In Fig. 14, the data in set \#1 to \#4 that were used for deriving this equation are shown by black 
Table 7 The coefficients of the multivariate linear regression

\begin{tabular}{|c|c|c|c|c|}
\hline & Estimated coefficient & Standard error & $t$ statistics & $p$ value \\
\hline Intercept & 7.7229 & 0.6289 & 12.2801 & $4.7522 \mathrm{e}-11$ \\
\hline$I T$ & -0.3214 & 0.0302 & -10.6532 & $6.3256 \mathrm{e}-10$ \\
\hline$D$ & -0.3959 & 0.0959 & -4.1307 & $4.7536 \mathrm{e}-4$ \\
\hline$I T \times D$ & 0.0178 & 0.0046 & 3.8616 & $9.0402 \mathrm{e}-4$ \\
\hline$I T^{2}$ & $-1.7903 e-4$ & $7.0887 \mathrm{e}-4$ & -0.2526 & 0.8031 \\
\hline$D^{2}$ & 0.0073 & 0.0031 & 2.3177 & 0.0306 \\
\hline$I T^{2} \times D$ & $1.1349 \mathrm{e}-6$ & $1.0804 \mathrm{e}-4$ & 0.0105 & 0.9917 \\
\hline$I T \times D^{2}$ & $-3.1759 \mathrm{e}-4$ & $1.5038 \mathrm{e}-4$ & -2.1119 & 0.0469 \\
\hline$I T^{2} \times D^{2}$ & $-4.5056 \mathrm{e}-07$ & $3.5333 \mathrm{e}-06$ & -0.1275 & 0.8997 \\
\hline $\begin{array}{l}\text { Full term regression } \\
\text { equation }\end{array}$ & $\begin{array}{l}\Delta T_{\max }=7.7229-0.3 \\
+0.017757(I T \times D) \\
+1.1349 e-6\left(I T^{2} \times\right. \\
-4.5056 e-7\left(I T^{2} \times\right.\end{array}$ & $\begin{array}{l}T)-0.39594(D \\
3 e-4\left(I T^{2}\right)+0 \\
.1759 e-4(I T \times\end{array}$ & $\left.D^{2}\right)$ & \\
\hline
\end{tabular}

dots. Set \#5 and \#6 that were used for validation of Eq. 4 are shown by red dots. Fig. 14(a) shows the overall form of this function and Fig. 14(b) shows the view along the defect depth axis to facilitate the comparison between model and measurements. Furthermore, the measured and predicted maximum temperature difference in set $\# 5$ and $\# 6$ of the experiments are compared in Table 8. This table shows that the equation can predict the measured temperature difference with acceptable accuracy based on the calculated percent error that is less than $7.27 \%$ in the validation procedure.

Table 9 compares Eq. 3 and Eq. 4, as well as a summary of the statistics of these equations. Equation 4 is based on 30 observations that leads to 24 degrees of freedom, while Eq. 3 is achieved based on 20 observations that leads to 14 degrees of freedom. By decreasing the number of observations (of course, not less than 20), the $\mathrm{R}$-squared values remain almost unchanged. This shows that a linear model explains over $99.5 \%$ of the variability in the data irrespective of the number of observations. Increasing the number of observations further improves the significance of the linear fit and model fitness compared to a degenerate model of a constant term as the $p$ value strongly decreases.

\section{Discussion}

The results for the temporal evolution of the thermal contrast and maximum thermal contrast measured using the IRT camera, and the thermocouples attached to the surface, were presented in the previous section, and are discussed in this section.

\subsection{Discussion of the IRT tests results}

Several experiments in a controlled environment using the IR camera showed this method could capture the trend of temperature difference variation with defect depth in a robust manner. Trendline trials of maximum thermal contrast show that it is nonlinearly related to the depth of defect. In an inverse power function relationship $\left(T_{\max } \propto D_{\text {def }}^{-\alpha}\right)$, the parameter $\alpha$ has a value of -0.62 . Moreover, the results show that for a specific slab, the effect of the initial temperature on the maximum thermal contrast is linear. Having identified the dependence of the thermal contrast on defect depth, and thermal contrast on initial temperature, an overall model for the thermal contrast dependence on these two variables was proposed. Upon considering the necessary terms in the regression modelling i.e., the terms without initial temperature raised to the power of two, the fitness of the model improves with an increase in the number of observations, but the coefficients of necessary terms do not exhibit significant change. The first partial derivative of Eq. 3 with respect to initial temperature (IT) is presented in Eq. 5 and shows that the variation of the function in the IT direction only depends on the defect depth $(D)$. Moreover, the first partial derivative of Eq. 3 with respect to defect depth $(D)$, is presented in Eq. 6 and shows that the variation of the function in the $\mathrm{D}$ direction depends on both $\mathrm{D}$ and IT.

$\frac{\partial \Delta T_{\max }}{\partial I T}=0.3286+0.0178(D)-3.3575 e-4\left(D^{2}\right)$,

$$
\begin{aligned}
\frac{\partial \Delta T_{\max }}{\partial D}= & -0.3951+0.0178(I T)+2 \times 0.00695(D) \\
& -2 \times 3.3575 e-4(I T \times D) .
\end{aligned}
$$




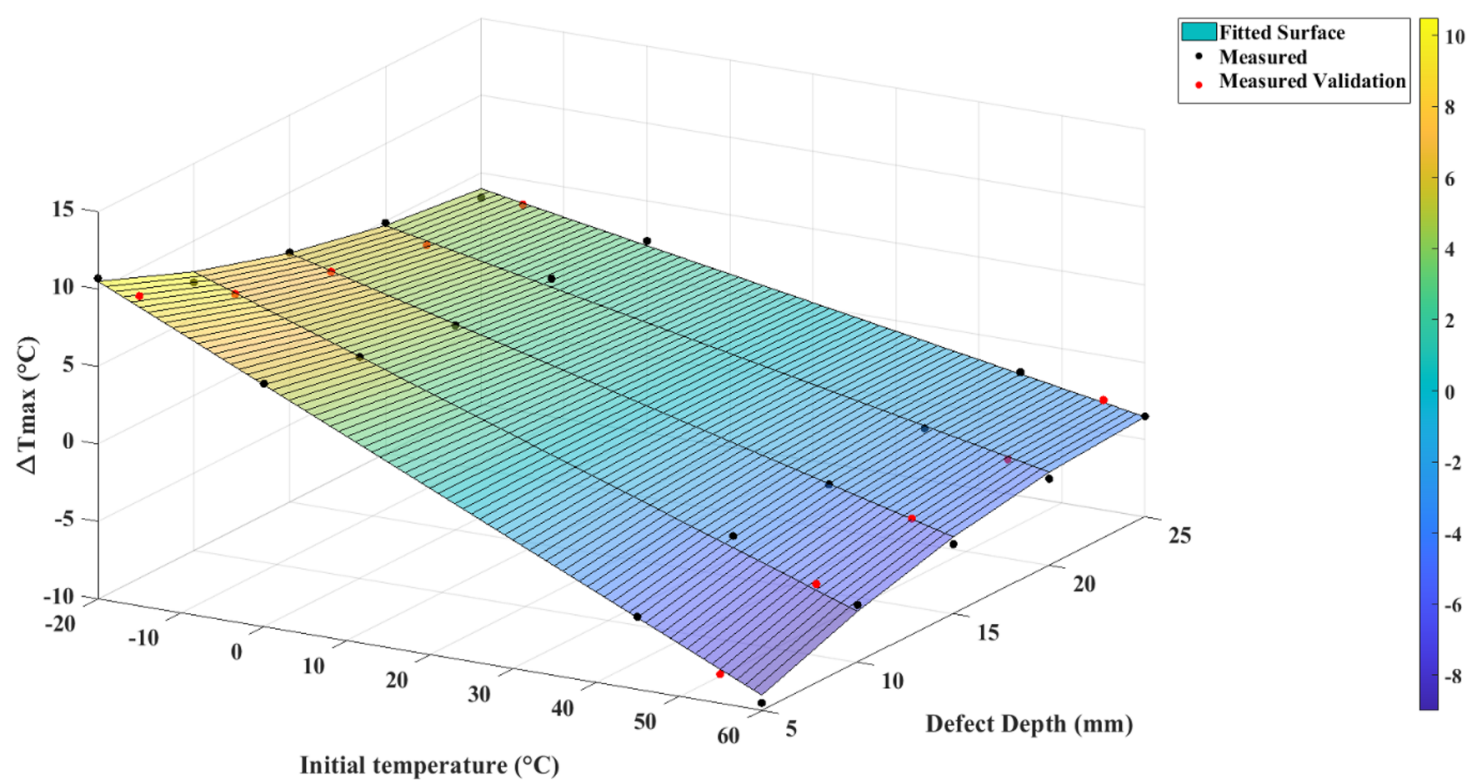

(a) The view with 30 degrees azimuth and 30 degrees elevation

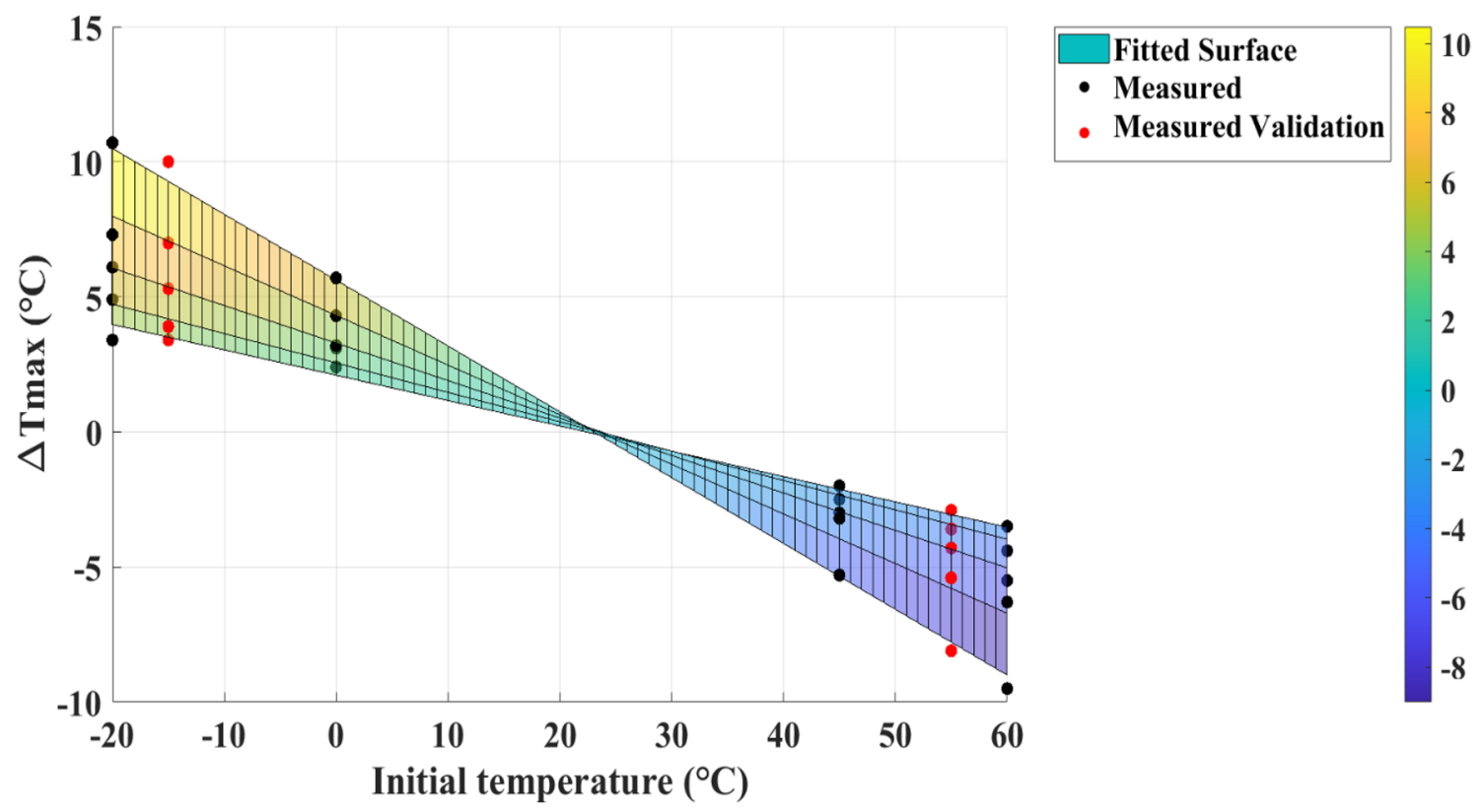

(b) The view with zero degree azimuth and zero degree elevation

Fig. 14 The dependence model of maximum thermal contrast on initial temperature, and defect depth (colour figure online) 
Table 8 Validation of the estimated $\Delta T_{\max }$

\begin{tabular}{llllllc}
\hline \multicolumn{7}{l}{ Slab code (defect depth) } \\
\cline { 3 - 7 } & & $\begin{array}{l}\text { SQ100-D05 } \\
(5 \mathrm{~mm})\end{array}$ & $\begin{array}{l}\text { SQ100-D10 } \\
(10 \mathrm{~mm})\end{array}$ & $\begin{array}{l}\text { SQ100-D15 } \\
(15 \mathrm{~mm})\end{array}$ & $\begin{array}{l}\text { SQ100-D20 } \\
(20 \mathrm{~mm})\end{array}$ & $\begin{array}{l}\text { SQ100-D25 } \\
(25 \mathrm{~mm})\end{array}$ \\
\hline $\begin{array}{l}\text { Set \#5 } \\
\left(\mathrm{IT}=-15{ }^{\circ} \mathrm{C}\right)\end{array}$ & $\begin{array}{l}\text { Measured } \\
\left({ }^{\circ} \mathrm{C}\right)\end{array}$ & 10 & 7 & 5.3 & 3.9 & 3.4 \\
& Predicted $\left({ }^{\circ} \mathrm{C}\right)$ & 9.2749 & 7.0676 & 5.3704 & 4.1834 & 3.5066 \\
& Percent error $(\%)$ & $7.25 \%$ & $0.96 \%$ & $1.32 \%$ & $7.26 \%$ & $3.1352 \%$ \\
Set \#6 & Measured & -8.1 & -5.4 & -4.3 & -3.6 & -2.9 \\
$\left(\mathrm{IT}=55{ }^{\circ} \mathrm{C}\right)$ & $\left({ }^{\circ} \mathrm{C}\right)$ & & & & & \\
& Predicted $\left({ }^{\circ} \mathrm{C}\right)$ & -7.7845 & -5.7927 & -4.3416 & -3.4309 & -3.0607 \\
& percent error $(\%)$ & $3.89 \%$ & $7.27 \%$ & $0.97 \%$ & $4.7 \%$ & $5.54 \%$ \\
\hline
\end{tabular}

Table 9 Summary of $\Delta T_{\max }$ multivariate equations

\begin{tabular}{|c|c|c|c|c|c|}
\hline \multirow[t]{2}{*}{ Equation 3} & \multicolumn{5}{|c|}{$\Delta T_{\max }=7.5965-0.3286(I T)-0.3951(D)+0.0178(I T \times D)+0.00695\left(D^{2}\right)-3.3575 e-4\left(I T \times D^{2}\right)$} \\
\hline & $\begin{array}{l}\text { Number of observations }= \\
30\end{array}$ & $\begin{array}{l}\text { Error degrees of freedom }= \\
24\end{array}$ & $\begin{array}{l}R \text {-squared }=0.996 \\
\text { Adjusted } \\
R \text {-squared }= \\
0.995\end{array}$ & $\begin{array}{lc}\text { RMSE }= & F \text { statistic vs. constant } \\
0.377 & \text { model }=1260\end{array}$ & $\begin{array}{l}p \text { value }= \\
3.18 \mathrm{e}-28\end{array}$ \\
\hline \multirow[t]{2}{*}{ Equation 4} & \multicolumn{5}{|c|}{$\Delta T_{\max }=7.2118-0.3187(I T)-0.3470(D)+0.0165(I T \times D)+0.0057\left(D^{2}\right)-3.0019 e-4\left(I T \times D^{2}\right)$} \\
\hline & $\begin{array}{l}\text { Number of observations }= \\
20\end{array}$ & $\begin{array}{l}\text { Error degrees of freedom }= \\
14\end{array}$ & $\begin{array}{l}\text { R-squared }=0.995 \\
\text { Adjusted } \\
R \text {-squared }= \\
0.993\end{array}$ & $\begin{array}{l}\text { RMSE }=\quad F \text { statistic vs. constant } \\
0.44 \quad \text { model }=582\end{array}$ & $\begin{array}{l}p \text { value }= \\
1.02 \mathrm{e}-15\end{array}$ \\
\hline
\end{tabular}

\subsection{Discussion of the thermocouple test results}

For the case of observations using thermocouples (contactbased temperature measurement sensors), the general considerations are related to the sensor attachment technique, and the relative size of the thermocouple bead $(0.25 \mathrm{~mm}$ diameter in this study) compared to the aggregate size used in the concrete, subsurface defect geometry and concrete surface finish condition. In these tests, a thermally conductive silicone paste and electrical tape were used to attach the bead of the thermocouple to the concrete surface. The thermocouples on the surface in a transient cooling or heating process are exposed to the motion of air, hence raising the possibility of error in the measurements due to combined convection and conduction heat transfer through the surface. Therefore, selection of an effective contact-based temperature sensor adds to the challenges of surface temperature measurement of concrete slabs as it might not achieve enough contact with the surface. In contrast, the infrared sensor provides a two-dimensional image-like measure of the whole target surface with the emission intensity of points on the surface translated to temperatures at corresponding pixel locations that conforms with the heat transfer pattern in the slab. The observations made in the results section (in addition to further observations by the authors throughout the experimental studies) on the variation of thermal contrast against the void depth, showed that the thermocouples did not perform reliably in tracking a unique pattern of the thermal contrast variation against the tested range of variation of concrete over defect.

\section{Conclusions and future research}

This paper presents the results of experimental IRT investigations performed on concrete test slabs with voids, simulating subsurface defects, embedded at various depths beneath the surface. This paper addresses the research gap in the application of convection heat exchange mechanism to the detection of hidden defects in concrete structures and identifies a trend of thermal contrast variation with defect depth. In these studies, the environmental chamber is used to achieve uniform initial temperatures throughout the slabs and hence to initiate convective heating and cooling of the slabs. Several initial temperatures were trialled to calculate and compare the absolute thermal contrast of the concrete on the void (damaged) and the sound concrete. Based on the results of this study, the initial temperature of slabs is 
linearly related to the surface thermal contrast of each sample (with specific defect depth). The overall equation for the relationship between the maximum thermal contrast as the dependent variable and initial temperature and void depth as the independent variables is also represented by a multivariate linear regression. This model can establish a basis for decision-making about the necessary environment for detection of a defect at a certain depth and it can be elaborated in future studies for other defect variables such as size and thickness. These observations confirm the potential of IRT as a non-contact and non-destructive method that can identify subsurface defects at various depths with acceptable accuracy if the environmental and excitation conditions are properly adopted. Furthermore, the presented mathematical model provides a basis for decision-making in practical implementation of IRT. Having established the trend of thermal contrast with convection heat exchange as an excitation, future studies can focus on the comparison of the variation of thermal contrast caused by excitation power from other sources such as IR radiator heater, solar irradiance and so on, to further address the practical challenges of IRT implementation for structural health monitoring of concrete civil infrastructure and to develop numerical models based on these experimental observations.

Acknowledgements This paper delivers the outputs of EPSRC-funded research in the Civil Engineering Department at Queen's University Belfast (QUB) in association with a wider USA-Ireland Research project funded by DfE (NI), SFI (Ireland) and NSF (USA). The authors would like to thank Dr. Sreejith Nanukuttan (lecturer), Dr. Jacek Kwasny (Research Fellow), and Mr. Kenny McDonald, Mr. James Laing, Mr. Edward Moulds, and Mr. Desmond Hill (technical staffs in the heavy structural laboratory) in QUB for the support provided to this research.

Funding The funding for the $\mathrm{PhD}$ research was through Engineering and Physical Sciences Research Council (EPSRC) DTP and the research was part of a wider USA-Ireland funded project 'Mobile Automated Rovers Fly-By (MARS-FLY) for Bridge Network Resiliency'.

Data availability The data that supports the findings of this study are available from the corresponding author upon request.

Code availability The MATLAB scripts developed for the analysis of IRT images are available from the corresponding author upon request.

Open Access This article is licensed under a Creative Commons Attribution 4.0 International License, which permits use, sharing, adaptation, distribution and reproduction in any medium or format, as long as you give appropriate credit to the original author(s) and the source, provide a link to the Creative Commons licence, and indicate if changes were made. The images or other third party material in this article are included in the article's Creative Commons licence, unless indicated otherwise in a credit line to the material. If material is not included in the article's Creative Commons licence and your intended use is not permitted by statutory regulation or exceeds the permitted use, you will need to obtain permission directly from the copyright holder. To view a copy of this licence, visit http://creativecommons.org/licenses/by/4.0/.

\section{References}

1. Uddin MM, Devang N, Azad AKM, Demir V (2019) Remote structural health monitoring for bridges. Springer International Publishing, Cham

2. Solla M, Lagüela S, Fernández N, Garrido I (2019) Assessing rebar corrosion through the combination of nondestructive GPR and IRT methodologies. Remote Sensing 11(14):1705. https://doi. org/10.3390/rs 11141705

3. Janků M, Cikrle P, Grošek J, Anton O, Stryk J (2019) Comparison of infrared thermography, ground-penetrating radar and ultrasonic pulse echo for detecting delaminations in concrete bridges. Constr Build Mater 225:1098-1111. https://doi.org/10.1016/j.conbu ildmat.2019.07.320

4. Grattan SKT, Taylor SE, Sun T, Basheer PAM, Grattan KTV (2009) Monitoring of corrosion in structural reinforcing bars: performance comparison using fiber-optic and electric wire strain gauge systems. IEEE Sens J 9(11):1494-1502. https://doi.org/10. 1109/JSEN.2009.2019348

5. Grattan SKT et al (2007) Corrosion induced strain monitoring through fibre optic sensors. J Phys 85:012017. https://doi.org/10. 1088/1742-6596/85/1/012017

6. Endsley A, Brooks C, Harris D, Ahlborn T, Vaghefi K (2012) Decision support system for integrating remote sensing in bridge condition assessment and preservation. In: SPIE Smart Structures and Materials + Nondestructive Evaluation and Health Monitoring. SPIE.

7. Doshvarpassand S, Wu C, Wang X (2019) An overview of corrosion defect characterization using active infrared thermography. Infrared Phys Technol 96:366-389. https://doi.org/10.1016/j.infra red.2018.12.006

8. Hiasa S, Birgul R, Catbas FN (2016) Infrared thermography for civil structural assessment: demonstrations with laboratory and field studies. J Civ Struct Heal Monit 6(3):619-636. https://doi. org/10.1007/s13349-016-0180-9

9. Clark MR, McCann DM, Forde MC (2003) Application of infrared thermography to the non-destructive testing of concrete and masonry bridges. NDT E Int 36(4):265-275. https://doi.org/10. 1016/S0963-8695(02)00060-9

10. Hiasa S, Birgul R, Catbas FN (2017) Investigation of effective utilization of infrared thermography (IRT) through advanced finite element modeling. Constr Build Mater 150:295-309. https://doi. org/10.1016/j.conbuildmat.2017.05.175

11. Hiasa S, Birgul R, Catbas FN (2017) Effect of defect size on subsurface defect detectability and defect depth estimation for concrete structures by infrared thermography. J Nondestr Eval 36(3):1-21. https://doi.org/10.1007/s10921-017-0435-3

12. Raja BNK et al (2020) The influence of ambient environmental conditions in detecting bridge concrete deck delamination using infrared thermography (IRT). Struct Control Health Monitor. https://doi.org/10.1002/stc.2506

13. Vaghefi K et al (2012) Evaluation of commercially available remote sensors for highway bridge condition assessment. J Bridg Eng 17(6):886-895. https://doi.org/10.1061/(ASCE)BE.19435592.0000303

14. Hiasa S, Catbas FN, Matsumoto M, Mitani K (2017) Considerations and issues in the utilization of infrared thermography for concrete bridge inspection at normal driving speeds. J Bridge Eng 22(11):04017101. https://doi.org/10.1061/(ASCE)BE.1943-5592. 0001124

15. Washer G, Fenwick R, Bolleni N (2009) Development of handheld thermographic inspection technologies [2009-08]. Missouri University of Science and Technology. Center for Transportation.

16. Kee S-H, Oh T, Popovics JS, Arndt RW, Zhu J (2012) Nondestructive bridge deck testing with air-coupled impact-echo and 
infrared thermography. J Bridg Eng 17(6):928-939. https://doi. org/10.1061/(ASCE)BE.1943-5592.0000350

17. Huh J et al (2016) Experimental study on detection of deterioration in concrete using infrared thermography technique. Adv Mater Sci Eng 2016:1053856. https://doi.org/10.1155/2016/10538 56

18. Omar T, Nehdi ML, Zayed T (2018) Infrared thermography model for automated detection of delamination in RC bridge decks. Constr Build Mater 168:313-327. https://doi.org/10.1016/j.conbuildmat.2018.02.126

19. Omar T, Nehdi ML (2017) Remote sensing of concrete bridge decks using unmanned aerial vehicle infrared thermography. Autom Constr 83:360-371. https://doi.org/10.1016/j.autcon.2017. 06.024

20. Milovanović B, Banjad Pečur I (2016) Review of active IR thermography for detection and characterization of defects in reinforced concrete. J Imaging 2(2):11. https://doi.org/10.3390/jimag ing2020011

21. Yehia S, Abudayyeh O, Nabulsi S, Abdelqader I (2007) Detection of common defects in concrete bridge decks using nondestructive evaluation techniques. J Bridg Eng 12(2):215-225. https://doi.org/ 10.1061/(ASCE) 1084-0702(2007)12:2(215)

22. Washer G, Fenwick R, Bolleni N (2010) Effects of solar loading on infrared imaging of subsurface features in concrete. J Bridg Eng 15(4):384-390. https://doi.org/10.1061/(ASCE)BE.19435592.0000117

23. Watase A et al (2015) Practical identification of favorable time windows for infrared thermography for concrete bridge evaluation. Constr Build Mater 101:1016-1030. https://doi.org/10. 1016/j.conbuildmat.2015.10.156

24. Washer G, Trial M, Jungnitsch A, Nelson S (2015) Field testing of hand-held infrared thermography, phase II

25. Pollock DG, Dupuis KJ, Lacour B, Olsen KR (2008) Detection of voids in prestressed concrete bridges using thermal imaging and ground-penetrating radar. Washington State Transportation Center (TRAC)

26. Rozanski L, Ziopaja K (2019) Applicability analysis of IR thermography and discrete wavelet transform for technical conditions assessment of bridge elements. Quant Infrared Thermogr J 16(1):87-110. https://doi.org/10.1080/17686733.2018.1480307

27. Maierhofer C, Brink A, Röllig M, Wiggenhauser H (2002) Transient thermography for structural investigation of concrete and composites in the near surface region. Infrared Phys Technol 43(3):271-278. https://doi.org/10.1016/S1350-4495(02)00151-2

28. Maierhofer $\mathrm{C}$ et al (2006) Application of impulse-thermography for non-destructive assessment of concrete structures. Cement Concr Compos 28(4):393-401. https://doi.org/10.1016/j.cemco ncomp.2006.02.011

29. Cotič P, Kolarič D, Bosiljkov VB, Bosiljkov V, Jagličić Z (2015) Determination of the applicability and limits of void and delamination detection in concrete structures using infrared thermography. NDT and E Int 74:87-93. https://doi.org/10.1016/j. ndteint.2015.05.003

30. Grattan SKT (2010) Development of fibre optic sensors for monitoring $\mathrm{pH}$ and reinforcement corrosion in concrete. Queen's University Belfast, Belfast

31. Różański L, Ziopaja K (2019) Applicability analysis of IR thermography and discrete wavelet transform for technical conditions assessment of bridge elements. Quant InfraRed Thermogr J 16(1):87-110. https://doi.org/10.1080/17686733.2018.1480307

32. Pozzer S, Pravia ZMC, Rezazadeh Azar E, Dalla Rosa F (2020) Statistical analysis of favorable conditions for thermographic inspection of concrete slabs. J Civil Struct Health Monit 10(4):609-626. https://doi.org/10.1007/s13349-020-00405-4

33. Cotič P, Jagličić Z, Niederleithinger E, Stoppel M, Bosiljkov V (2014) Image fusion for improved detection of near-surface defects in NDT-CE using unsupervised clustering methods. J Nondestr Eval 33(3):384-397. https://doi.org/10.1007/s10921-014-0232-1

34. Tran QH, Han D, Kang C, Haldar A, Huh J (2017) Effects of ambient temperature and relative humidity on subsurface defect detection in concrete structures by active thermal imaging. Sensors-Basel 17(8):1718. https://doi.org/10.3390/s17081718

35. Waldemar M, Klecha D (2015) Modeling of atmospheric transmission coefficient in infrared for thermovision measurements. In: Proceedings of the Sensor

36. Systems F (2009) User's manual-FLIR B series; FLIR T series. [21 May 2021]; Available from: https://www.instrumart.com/ assets/B-Tseries-manual.pdf.

37. Tran QH, Huh J, Mac VH, Kang C, Han D (2018) Effects of rebars on the detectability of subsurface defects in concrete bridges using square pulse thermography. NDT and E Int 100:92-100. https:// doi.org/10.1016/j.ndteint.2018.09.001

38. Chen H-Y, Chen C (2016) Determining the emissivity and temperature of building materials by infrared thermometer. Constr Build Mater 126:130-137. https://doi.org/10.1016/j.conbuildmat. 2016.09.027

39. Janků M, Březina I, Grošek J (2017) Use of infrared thermography to detect defects on concrete bridges. Proc Eng 190:62-69. https:// doi.org/10.1016/j.proeng.2017.05.308

40. Holman JP (2010) Heat transfer. 10th edn. McGraw-Hill series in mechanical engineering. McGraw Hill Higher Education, Boston, xxii, p 725

41. MathWorks (2021) Interpret linear regression results. [cited 2021 06/07/2021]; Available from: https://uk.mathworks.com/help/ stats/understanding-linear-regression-outputs.html\#InterpretL inearRegressionResultsExample-1.

Publisher's Note Springer Nature remains neutral with regard to jurisdictional claims in published maps and institutional affiliations. 